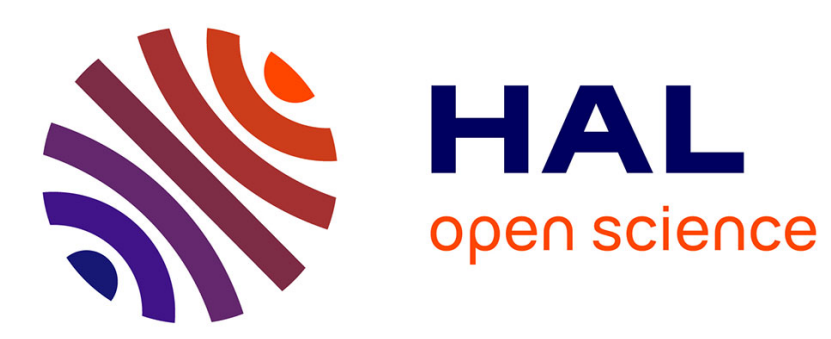

\title{
The use of rush deliveries in periodic review assemble-to-order systems
}

Mohammed Hichame Benbitour, Evren Sahin, Yves Dallery

\section{To cite this version:}

Mohammed Hichame Benbitour, Evren Sahin, Yves Dallery. The use of rush deliveries in periodic review assemble-to-order systems. International Journal of Production Research, 2019, 57 (13), pp.40784097. 10.1080/00207543.2018.1505059 . hal-01997380

\section{HAL Id: hal-01997380 \\ https://hal.science/hal-01997380}

Submitted on 16 Sep 2020

HAL is a multi-disciplinary open access archive for the deposit and dissemination of scientific research documents, whether they are published or not. The documents may come from teaching and research institutions in France or abroad, or from public or private research centers.
L'archive ouverte pluridisciplinaire HAL, est destinée au dépôt et à la diffusion de documents scientifiques de niveau recherche, publiés ou non, émanant des établissements d'enseignement et de recherche français ou étrangers, des laboratoires publics ou privés. 


\title{
The Use of Rush Deliveries in Periodic Review Assemble-to-Order Systems
}

\author{
Mohammed Hichame BENBITOUR, Evren SAHIN, Yves DALLERY
}

Université Paris-Saclay, CentraleSupélec, Laboratoire Genie Industriel, Gif-sur-Yvette, France, 91190

mohammed-hichame.benbitour@centralesupelec.fr, evren.sahin@centralesupelec.fr, yves.dallery@ centralesupelec.fr

\begin{abstract}
We calculate optimal safety stock in a periodic review $(T, S)$ Assemble-to-Order system having multiple components and multiple finished goods. Customer orders for finished goods arrive according to independent Poisson processes, and cannot be neither backlogged nor lost. In case of potential component stock-out, the studied system uses rush deliveries from suppliers. For this setting, approximate expressions of the optimal safety stock that minimize the sum of inventory holding and rush ordering costs are developed. Exact optimal safety stocks are calculated using discrete event simulation, and compared numerically to the approximate expressions. The model is applied to a first-tier automotive supplier and yields to a significant reduction in terms of inventory holding and rush ordering costs. A sensitivity analysis on relevant system parameters such as components demand, assembly coefficients and unit rush ordering cost is conducted.
\end{abstract}

Keywords: inventory control; assemble-to-order; periodic review; rush orders; optimization;

\section{Introduction}

In this paper, we develop a new model of components safety stocks calculation in Assembleto-Order (ATO) systems. As defined by Song and Zipkin (2003), an ATO system includes components and finished goods (FGs) where demands occur for FGs, and inventory is kept for components (i.e., there is no inventory for FGs). It has been shown in practice that ATO systems can be successfully applied in situations where there is a high diversity of FGs, where FGs can be quickly assembled and where holding FGs inventory is costly. For instance, ATO systems 
are widely applied in automotive, aerospace and computer industries. The replenishment and the allocation of components inventory constitute the main inventory decisions in ATO systems. The replenishment decision consists in determining when to order components and in what quantity. Components inventory allocation is to decide how much inventory to allocate per FG and/or customer class.

The model we develop is inspired from the operating conditions of a production environment observed in company "Alpha" plants. Indeed, Alpha is one of the world's top ten auto parts makers (the company name has been altered for confidentiality reasons). Alpha customers seek a $100 \%$ service level from first-tier suppliers such as Alpha. The activity of OEMs is indeed organized in a way that any backorder or waiting time generate important costs. As Boysen et al. (2015) detailed, the different reactions that occur when there is a stock-out at the assembly line of OEMs cause high penalty costs. Hence, first-tier suppliers have a tendency to over-estimate their components safety stocks in order to guarantee the OEMs constraint (100\% service level). At the same time, satisfying customer demands in ATO systems without keeping inventory of FGs makes the control of components inventory of paramount importance. Traditional replenishment policies (such as reorder point, order up-to, etc) may reveal insufficient to keep high customer service levels. This increases the need to couple those policies with alternative (more flexible) replenishment practices. For instance, adding rush supply to regular supply (which is used in traditional replenishment policies) has been proved to be a promising strategy to improve service level and avoid stock-outs (Tagaras and Vlachos 2001). Nevertheless, rush orders are subject to a higher ordering cost (higher than the regular order cost). The use of rush orders is observed in the automotive industry between first-tier suppliers and second-tier suppliers. Companies like Alpha use rush ordering (with an additional cost compared to standard ordering) to receive emergency deliveries in case of potential components stock-outs. 
Another important factor that motivates the use of rush deliveries in the automotive industry is related to Just-in-Time deliveries. Alpha (as well as other first-tier suppliers) uses Just-in-Time delivery, i.e., instead of receiving from their suppliers a shipment in full (one shipment for one regular order), the regular order is smoothed into multiple shipments. For instance, more than $74 \%$ of components in an Alpha plant (situated in France) are delivered in multiple shipments. This strategy allows indeed to reduce components inventory levels, but increases the risk of stock-outs. Therefore, having the option of rush ordering (which reduces the risk of stock-outs) can compensate the drawbacks of reduction of inventory levels.

At the beginning of the project, Alpha plants were using a safety stock calculation model that resulted in over-estimations of components safety stocks. Additionally, this model was difficult to interpret for procurement managers and did not take into account inventory holding and rush ordering costs in the calculation (all components were considered in the same way despite the differences in unit inventory holding and rush ordering costs among product categories). Managers then decided to adjust the calculation method by using empirically defined reduction percentages that depend on the nature of components (high vs. low runner products). The calculation method obtained was still not fully satisfactory. Hence, the decision was to develop a new safety stock calculation model corresponding to Alpha replenishment environment.

In the model we develop, we consider an ATO system with multiple FGs and multiple components. A periodic review order up-to $(T, S)$ policy is used to replenish components inventory. Suppliers of components deliver an order in multiple shipments (rather than a single shipment). In case of potential shortage, suppliers offer the option of using rush orders at a higher ordering cost. FGs demand must be satisfied totally without tardiness (neither backlogging nor lost sale are possible). 
We propose an approximate analytical model to calculate numerically the optimal safety stock of a component in order to minimize the average inventory holding and rush ordering costs. Then, we use a Discrete Event Simulation model developed in Matlab to verify the effectiveness of the approximate model. Finally, a sensitivity analysis on the impact of different system parameters such as components demand, number of shipments, assembly coefficient, and unit rush ordering cost is developed.

This paper is organized as follows, section 2 provides a summary of the related literature. In section 3, we describe the model developed. Expressions of the optimal component safety stock and optimal total cost are given in section 4. In section 5, results obtained from the approximate model are compared to the optimal values calculated by the Discrete Event Simulation model. A sensitivity analysis on the impact of different system parameters is conducted in section 6 . Finally, section 7 concludes the paper.

\section{Literature review}

Our study is related to two research streams: components inventory control in ATO systems, and the use of rush orders (also called emergency shipments in the literature) in inventory systems.

The literature on ATO systems mainly addresses the problems of components inventory replenishment and inventory allocation. Agrawal and Cohen (2001) derived expressions to calculate optimal base stock levels for components under a constraint on FGs service described by order completion rate. Authors assume a fair shares allocation policy where the fraction of component inventory allocated to a FG is equal to the quotient of its demand and the total demand of FGs. A general literature review of ATO system was provided by Song and Zipkin (2003) where they classified the different models into: one period models, discrete time multiperiod models and continuous time models. Atan et al. (2017) gave an update of the literature 
on ATO systems following the same classification. Akçay and Xu (2004) studied the calculation of the optimal base stock levels for an ATO system with multiple products and components where products demand is correlated. In a two stage stochastic decision model, the authors studied also the optimal allocation problem and proposed a simple component allocation rule.

In a single FG, multiple components and multiple customer classes (with different lost sale costs) ATO system, Benjaafar and ElHafsi (2006) studied the optimal production control and inventory allocation problem where each customer class demand follows a Poisson distribution. They considered two configurations: backorders and lost sales. Authors found that the optimal components production (replenishment) policy is a state-dependent base stock policy and the optimal allocation policy is a state-dependent rationing policy. ElHafsi et al. (2008) studied a specific ATO configuration (modular nested design) where they provided the structure of the optimal production control and allocation policies. They assumed a Poisson customer demand with lost sales possibility. The authors found the same optimal structure found by Benjaafar and ElHafsi (2006).

Zhao (2009) gave exact and approximate values of performance metrics for an ATO system with multiple components and FGs, which uses a continuous time $(R, Q)$ batch ordering policy with possibility of splitting orders (i.e., satisfying an order separately and not in full). In a one period ATO system with one FG and multiple components, Xiao et al. (2010) determined the optimal inventory and production decisions using a two stage decision model within an environment of uncertain demand and uncertain assembly capacity. They assumed the possibility of using rush deliveries and in-advance assembly. Fu et al. (2011) studied a multiple FGs and components ATO system with backlogging possibility and FCFS allocation policy. The authors proposed approximation methods to calculate three performance measures: average waiting time, fill rate and average number of backorders. Karaarslan et al. (2013) compared 
between two inventory control policies (pure base stock policy, and balanced base stock policy) for an ATO system with one FG and two components. ElHafsi et al. (2015) determined the optimal component production and allocation policy for an ATO system with one FG and multiple components. They assumed that demand can occur for both FG and components where unsatisfied demand is lost. They compare the optimal policy (state-dependent base stock and rationing policy) to three heuristic policies.

In our paper, we study the calculation of optimal safety stocks (deducted from the calculation of optimal order up-to levels) in periodic review ATO systems. Babai et al. (2011) proposed a method to calculate the optimal order up-to level in a single stage, single item inventory system where customer orders arrive according to a compound Poisson process and unmet demand is backordered. Jalali and Nieuwenhuyse (2015) surveyed the literature on simulation optimization techniques used to solve complex inventory problems. In a periodic review capacitated multi-echelon assembly system, Woerner et al. (2017) proposed an approximate method to resolve the joint optimization problem of safety stock and capacity allocation. Desmet et al. (2010) proposed an approximation model to calculate optimal safety stock in a two-echelon assembly system.

There exists also some papers that studied the use of rush orders as an alternative supply mode and evaluated its impact on inventory control problems. Smith (1977) studied the use of emergency shipments in an inventory system controlled by the base stock policy $(S, S-1)$. The unmet demand is assumed to be lost (no backlogging). The author gave the optimal and approximate expression of calculation of the base stock level $S$. Moinzadeh and Schmidt (1991) studied the use of emergency orders in an inventory system that faces a Poisson demand and uses the $(S, S-1)$ policy. They proposed a policy to trigger emergency shipments, and evaluated the parameters of this policy as well as the optimal base stock level $S^{*}$. 
Tagaras and Vlachos (2001) studied the use of emergency shipments in an inventory system controlled with a periodic review $(T, S)$ policy, with backlogging possibility for unsatisfied customer demand. The authors gave an approximate model to calculate the optimal base stock level and the threshold used to trigger emergency replenishments. The approximate model is compared to the optimal solution (given by simulation). They justified the efficiency of the approximate solution, and showed that the use of emergency shipments can lead for interesting cost savings. In another study, the same authors (Vlachos and Tagaras 2001), considered a similar model but with a supplier capacity constraint on the rush delivered quantity. The authors compared between two emergency ordering policies "Early ordering" and "Late ordering". In the "Early ordering" policy, an emergency order is placed earlier in the replenishment cycle (the time interval that separates two regular deliveries) in order to reduce potential early stock-outs. On the other hand, the "Late ordering" policy places a replenishment order later in order to have more information about demand and stock-outs, hence the replenishment order size is better calculated. The "Early ordering" policy seems to be more interesting when variability of demand increases, shortage cost decreases, and delivery and period lead times become longer.

In an inventory system with continuous review $(R, Q)$ policy for normal supply, Axsäter (2007) proposed a decision rule to use emergency shipments. He showed the interest of using the proposed policy in a simulation study and pointed out the situations where it performs well. Dhawan et al. (2009) used neuro-dynamic programming to find the best quantity to order from two supply sources (regular and emergency) in order to minimize regular ordering, emergency ordering, shortage and inventory holding costs. Alvarez et al. (2013) studied the use of emergency replenishments in an inventory system that serves multiple customer classes for multiple items where the demand of each item follows a Poisson distribution. They proposed a policy to select for which item/customer class it is better to apply the emergency shipment 
option. Mardan et al. (2015) studied the use of emergency supply and emergency production in a Make-to-Stock system with multiple FGs and items. They proposed an integrated emergency ordering and production planning policy by resolving a two stage stochastic decision problem.

Zheng et al. (2015) studied a two stage decision problem where a regular (normal) supply order is placed in the first stage and an emergency supply order can be placed in the second stage based on the update of demand forecast. The authors used dynamic programming to determine the optimal ordering quantities within the two stages, and showed the interest of using emergency supply.

Table 1 summarizes the literature concerning rush orders. Each paper is described in terms of: inventory control policy used, rush ordering policy, probability distribution, cost parameters considered, type of optimization model used to calculate policy parameters. As reported, our work considers a multi-period ATO system controlled with a $(T, S)$ policy and assumes that customer demand cannot be backlogged nor lost. Since demand has to be totally satisfied, the definition of an inventory allocation policy is not required. Tagaras and Vlachos (2001), Vlachos and Tagaras (2001) are the nearest papers to ours: they considered a $(T, S)$ inventory system and developed an approximate model to calculate the optimal order up-to level $S$ and the threshold used to trigger rush orders. Our paper considers the components safety stocks problem at Alpha plants. Assumptions related to the industrial context of Alpha are as follows: i) we consider an ATO system where regular deliveries are received in multiple shipments (and not in a single shipment); ii) the rush ordering policy used triggers rush orders in case of potential stock-out; iii) OEM demand has to be totally satisfied (no backlog nor lost sales). To our knowledge, such assumptions are not taken altogether in previous studies. Our objective is to develop a model for optimal safety stocks for companies working in an ATO configuration similar to Alpha. 
Table 1. Papers dealing with rush orders

\begin{tabular}{|c|c|c|c|c|c|}
\hline Paper & $\begin{array}{l}\text { System considered and } \\
\text { regular ordering policy }\end{array}$ & $\begin{array}{c}\text { Rush ordering policy } \\
\text { (when is the rush order } \\
\text { triggered?) }\end{array}$ & $\begin{array}{c}\text { Demand } \\
\text { probability } \\
\text { distribution }\end{array}$ & $\begin{array}{l}\text { Costs considered } \\
\text { (fixed/variable) }\end{array}$ & $\begin{array}{l}\text { Optimization } \\
\text { model }\end{array}$ \\
\hline Smith (1977) & $(S, S-1)$ inventory system & $\begin{array}{c}\text { When an item is in stock- } \\
\text { out }\end{array}$ & Poisson & $\begin{array}{l}\text { Rush ordering cost (variable), } \\
\text { inventory holding cost (variable) }\end{array}$ & $\begin{array}{l}\text { Analytical model } \\
\text { (Queueing model) }\end{array}$ \\
\hline $\begin{array}{l}\text { Moinzadeh and } \\
\text { Schmidt (1991) }\end{array}$ & $(S, S-1)$ inventory system & $\begin{array}{l}\text { Heuristic that depends on } \\
\text { the normal and rush } \\
\text { delivery lead times in } \\
\text { order to decide whether to } \\
\text { use a normal or a rush } \\
\text { order }\end{array}$ & Poisson & $\begin{array}{c}\text { Regular ordering cost (variable), } \\
\text { rush ordering cost (variable), } \\
\text { inventory holding cost } \\
\text { (variable), back-order penalty } \\
\text { cost (variable), lost sale cost } \\
\text { (variable) }\end{array}$ & $\begin{array}{l}\text { Analytical model } \\
\text { (Queueing model) }\end{array}$ \\
\hline $\begin{array}{c}\text { Tagaras and } \\
\text { Vlachos (2001) }\end{array}$ & $(T, S)$ inventory system & $\begin{array}{l}\text { A threshold on the } \\
\text { inventory state }\end{array}$ & Normal, Erlang & $\begin{array}{l}\text { Additional cost of an emergency } \\
\text { order over that of a regular order } \\
\text { (variable), inventory holding } \\
\text { cost (variable), back-order } \\
\text { penalty cost (variable) }\end{array}$ & $\begin{array}{l}\text { Analytical model, } \\
\text { simulation }\end{array}$ \\
\hline Axsäter (2007) & $(R, Q)$ inventory system & $\begin{array}{c}\text { Heuristic decision rule } \\
\text { which assumes that there } \\
\text { is no possible future rush } \\
\text { orders }\end{array}$ & $\begin{array}{l}\text { Compound } \\
\text { Poisson }\end{array}$ & $\begin{array}{l}\text { Regular ordering cost (fixed), } \\
\text { rush ordering cost } \\
\text { (fixed+variable), inventory } \\
\text { holding cost (variable), back- } \\
\text { order penalty cost (variable) }\end{array}$ & Simulation \\
\hline
\end{tabular}




\begin{tabular}{|c|c|c|c|c|c|}
\hline $\begin{array}{l}\text { Dhawan et al. } \\
\qquad(2009)\end{array}$ & $\begin{array}{l}\text { Base stock for an } \\
\text { inventory/production } \\
\text { system }\end{array}$ & $\begin{array}{l}\text { A threshold on the on- } \\
\text { hand inventory }\end{array}$ & $\begin{array}{l}\text { Unspecified, use of } \\
\text { historical data }\end{array}$ & $\begin{array}{l}\text { Regular ordering cost (variable), } \\
\text { rush ordering cost (variable), } \\
\text { inventory holding cost } \\
\text { (variable), back-order penalty } \\
\text { cost (fixed) }\end{array}$ & $\begin{array}{c}\text { Analytical model } \\
\text { (Neuro-dynamic } \\
\text { programming) }\end{array}$ \\
\hline $\begin{array}{l}\text { Alvarez et al. } \\
\text { (2013) }\end{array}$ & $(S, S-1)$ inventory system & $\begin{array}{l}\text { When an item is in stock- } \\
\text { out of an item, the use of } \\
\text { emergency shipment } \\
\text { depends on the customer } \\
\text { class }\end{array}$ & $\begin{array}{l}\text { Multiple customer } \\
\text { classes with } \\
\text { Poisson demand }\end{array}$ & $\begin{array}{l}\text { Rush ordering cost (fixed), } \\
\text { inventory holding cost (variable) }\end{array}$ & $\begin{array}{l}\text { Heuristics (local } \\
\text { search, integer } \\
\text { programming) }\end{array}$ \\
\hline $\begin{array}{l}\text { Mardan et al. } \\
\quad(2015)\end{array}$ & $\begin{array}{l}\text { Two-stage decision- } \\
\text { making } \\
\text { inventory/production } \\
\text { system where optimal } \\
\text { regular order is } \\
\text { triggered in the first } \\
\text { stage }\end{array}$ & $\begin{array}{l}\text { Optimal rush order is } \\
\text { triggered in the second } \\
\text { stage (there is a similar } \\
\text { two-stage decision- } \\
\text { making process for } \\
\text { production planning) }\end{array}$ & Unspecified & $\begin{array}{l}\text { Regular ordering cost (variable), } \\
\text { rush ordering cost (variable), } \\
\text { inventory holding cost } \\
\text { (variable), back-order penalty } \\
\text { cost (variable), lost sale cost } \\
\text { (fixed), salvage cost (fixed) }\end{array}$ & $\begin{array}{l}\text { Sample average } \\
\text { approximation }\end{array}$ \\
\hline $\begin{array}{l}\text { Zheng et al. } \\
\text { (2015) }\end{array}$ & $\begin{array}{l}\text { Two-stage decision- } \\
\text { making newsvendor } \\
\text { system where optimal } \\
\text { regular order is } \\
\text { triggered in the first } \\
\text { stage }\end{array}$ & $\begin{array}{l}\text { Optimal rush order is } \\
\text { triggered in the second } \\
\text { stage based on the } \\
\text { forecasts update }\end{array}$ & $\begin{array}{l}\text { Normal, } \\
\text { Lognormal }\end{array}$ & $\begin{array}{l}\text { Regular ordering cost (variable), } \\
\text { rush ordering cost (variable), } \\
\text { salvage cost (variable) }\end{array}$ & $\begin{array}{l}\text { Analytical model } \\
\text { (Dynamic } \\
\text { programming) }\end{array}$ \\
\hline Our paper & $\begin{array}{l}(T, S) \text { with possibility of } \\
\text { receiving a regular order } \\
\text { in multiple shipments } \\
\text { for an ATO system }\end{array}$ & $\begin{array}{l}\text { In case of potential } \\
\text { component stock-out }\end{array}$ & $\begin{array}{l}\text { Compound } \\
\text { Poisson }\end{array}$ & $\begin{array}{l}\text { Rush ordering cost (fixed), } \\
\text { inventory holding cost (variable) }\end{array}$ & $\begin{array}{c}\text { Analytical model, } \\
\text { simulation }\end{array}$ \\
\hline
\end{tabular}




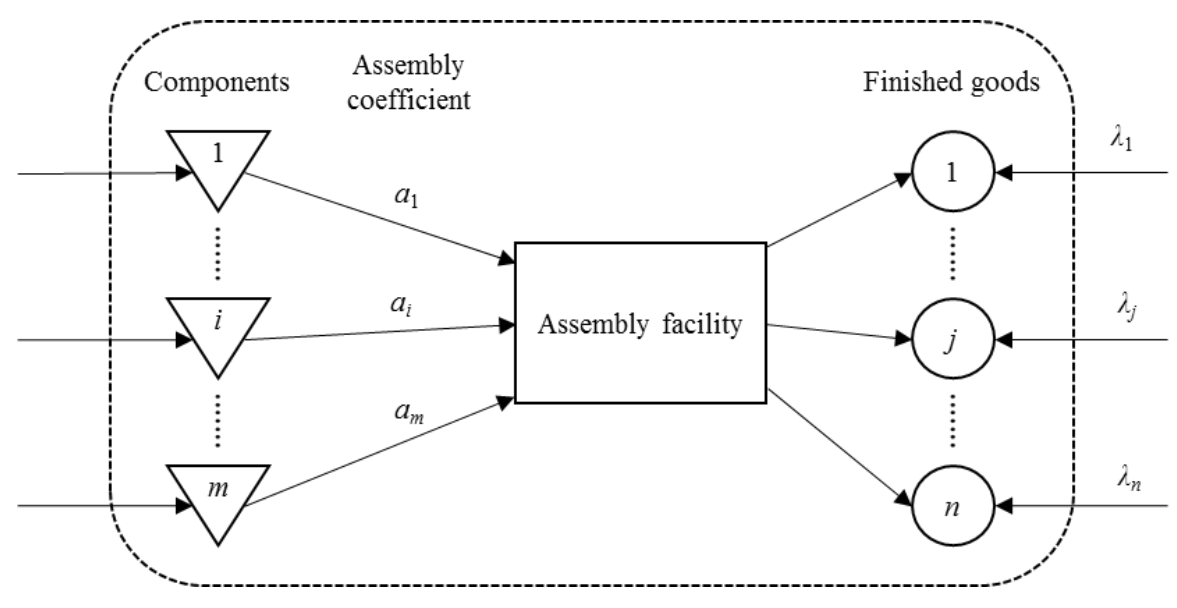

Figure 1. Assemble-to-Order system considered

\section{Model formulation}

We consider an ATO system with $n_{c}$ components and $n_{f}$ FGs (cf. Figure 1). The set of FGs is denoted by $F$. Each component $i$ is used by a set of FGs denoted by $F_{i}$ where $F_{i} \subseteq$ $F$ and $\cup_{i=1}^{n_{c}} F_{i}=F$. Each unit of FG $j$ uses $a_{i j}$ units of component $i$ in the assembly process. Customer orders for each FG $j$ are assumed to arrive according to an independent Poisson process with a mean arrival rate $\lambda_{j}$. As a result, each component $i$ is assumed to have a compound (batch) Poisson demand: i) the demand of each FG is assumed to be independent of the demand of other FGs, hence, the sum of customer orders for FGs that use the same component $i$ arrive according to a Poisson process, ii) the mean arrival rate of component $i$ demand, i.e., $\beta_{i}$, would be given by: $\beta_{i}=\sum_{j \in F_{i}} \lambda_{j}$. The number of units of component $i$, denoted by $X_{i}$, required for each customer order is a random variable with a probability distribution: $P\left(X_{i}=a_{i j}\right)=\frac{\lambda_{j}}{\beta_{i}}$.

Without loss of generality, we assume that each component $i$ has a constant assembly coefficient $a_{i}$ (i.e., $a_{i j}=a_{i}, \forall j \in F_{i}$ ). This assumption is not restrictive and is frequently observed in various industries (e.g., there are always two headrests in one car seats). Hence, each component $i$ has a compound Poisson demand with mean $\beta_{i} * a_{i}$ 
where the mean arrival rate is $\beta_{i}$, and size batch size equal to $a_{i}$.

We assume also that the assembly lead time of each FG is negligible, and the assembly capacity is sufficient to satisfy customer demand. Customer demand has to be totally satisfied and cannot be neither backlogged nor lost.

We assume the inventory of component $i$ is controlled by the periodic review $\left(T_{i}, S_{i}\right)$ policy where $T_{i}$ is the review time interval and $S_{i}$ is the order up-to level. In this policy, an order is sent to an external supplier each time interval $T_{i}$. The size of the order is the difference between $S_{i}$ and the inventory position at the moment of ordering. Components are received after a constant delivery lead time $D L T_{i}$. More particularly, we assume that the order is delivered in multiple shipments, i.e., instead of shipping the total quantity ordered after $D L T_{i}$, the supplier splits the order and sends $m_{i}$ equal parts of the order during the time interval $T_{\mathrm{i}}\left(m_{i}\right.$ is the number of shipments during $T_{i}$ and $\frac{T_{i}}{m_{i}}$ is the time interval between two consecutive shipments). Delivery in multiple shipments is a common practice in order to smooth (reduce) inventory levels.

In case of a potential stock-out for component $i$ (there is a stock-out when the onhand inventory is not sufficient to satisfy demand), the ATO system sends a rush order to the supplier with a fixed cost $R_{i}$. We assume that the rush order has a negligible lead time. We also assume that the supplier has the capacity necessary to satisfy rush orders.

We assume that time is discrete and divided into equal time units (e.g., days). Events that occur in a time unit $t$, for component $i$ are as follows: (cf. Figure 2)

(1) Inventory position is reviewed and a replenishment order is sent to supplier.

(2) Supplier shipment is received.

(3) Inventory holding costs are charged. 


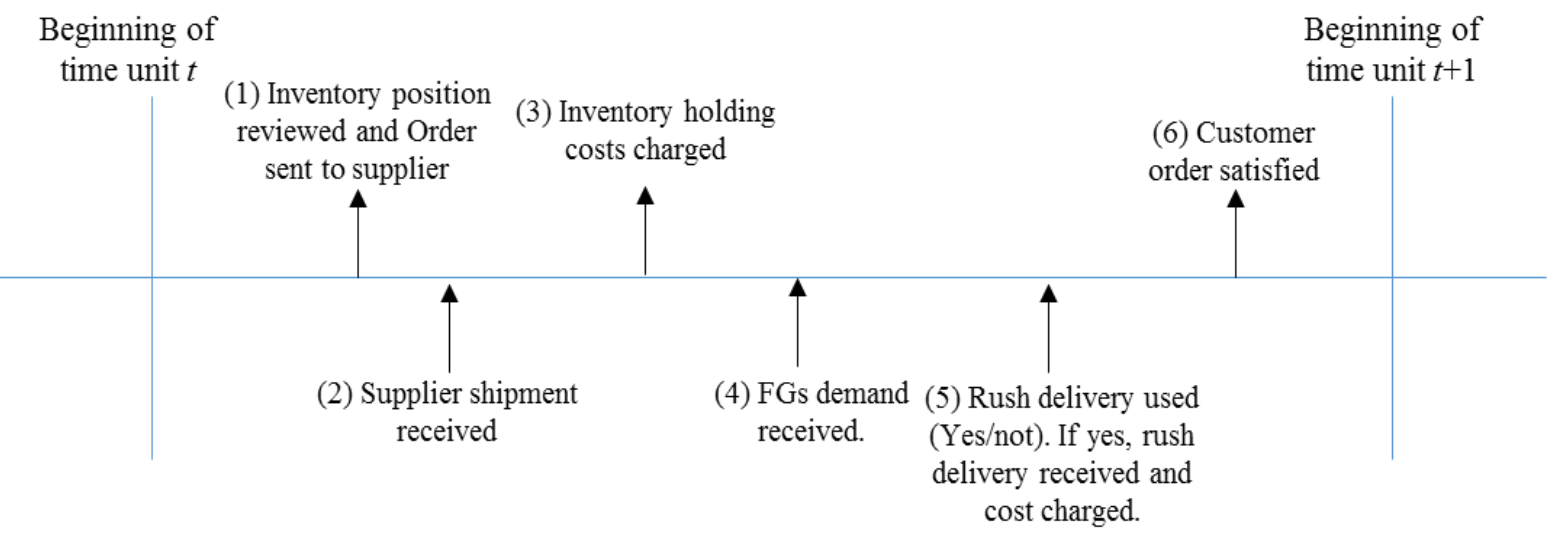

Figure 2. Sequence of events within each time unit

(4) FGs demand is received and the required component demand is calculated using the assembly coefficients given by the Bill of Materials (BOM).

(5) If component on-hand inventory is not sufficient to satisfy demand, a rush order for the missing quantity is sent to the supplier and fully received (rush order lead time is assumed negligible). A fixed rush ordering cost $R_{i}$ (cost/rush order) is charged. $R_{i}$ is assumed to not depend on quantity (i.e., units of component requested) and is assumed to be a fixed cost.

(6) Components are assembled (assembly capacity is assumed large) and FGs demand is totally satisfied.

Remarks below provide further details regarding the sequence of events:

- The first review of the inventory position for each component $i$ occurs at the beginning of time unit $t=1$. After, there is a review (and ordering) at the beginning of each time unit $t$ where $(t-1) \equiv 0\left(\bmod T_{i}\right)$.

- When a replenishment order for component $i$ is sent to the supplier in time unit $t$, then, the corresponding supplier shipments are received in time units:

$t+D L T_{i} ; t+D L T_{i}+\frac{T_{i}}{m_{i}} ; t+D L T_{i}+\frac{2 T_{i}}{m_{i}} ; \ldots ; t+D L T_{i}+\frac{\left(m_{i}-1\right) T_{i}}{m_{i}}$. We assume that $\frac{T_{i}}{m_{i}}$ is an integer. $m_{i}=1$ corresponds to the (classical) case where the (full) order is received in a single shipment.

The list of notations is given in Appendix 1. 
Table 2. Inventory units expressed in units or in batches of component

\begin{tabular}{ccc}
\hline & $\begin{array}{c}\text { Inventory expressed as } \\
\text { units of component }\end{array}$ & $\begin{array}{c}\text { Inventory expressed as batches } \\
\text { where } 1 \text { batch= } a \text { units of component }\end{array}$ \\
\hline Safety stock & $S S=a \times S S^{\text {batch }}$ & $S S^{\text {batch }}$ \\
\hline Order up-to level & $S=a \times S^{\text {batch }}$ & $S^{\text {batch }}$ \\
\hline $\begin{array}{c}\text { Unit inventory } \\
\text { holding cost per year }\end{array}$ & $h$ & $h^{\text {batch }}=a \times h$ \\
\hline
\end{tabular}

\section{Optimization of component safety stock}

The objective of the developed model is to find an optimal overall inventory policy which minimizes the expected total annual cost among all components. In our model, we assume that each component $i$ inventory is managed independently from the other components, hence, the optimal overall policy is deduced from the optimal inventory policy of each component. That is why, we determine the optimal inventory policy for a single component $i$ and apply it for all components. Henceforth, we omit the subscript $i$ from all variables.

The optimal inventory policy for a component is determined by calculating its optimal safety stock $S S$ and its optimal order up-to level $S$. As shown in section 3, component demand arrives in batch where the batch size is equal to $a$. Due to this property, and in order to facilitate understanding, the inventory model will be formulated in batches of size $a$. The corresponding notations and equivalences when inventory is expressed either in units of component or in batches of component are given in Table 2.

Once the optimal values of $S S^{\text {batch }}$ and $S^{\text {batch }}$ are calculated, the optimal values of $S S$ and $S$ will be deduced by using the relation given in Table 2. The optimization of time interval $T$ is not addressed in this model ( $T$ can be optimized using a method such as the economic order quantity). 
The expected total cost per year, denoted by $T C$, is the sum of the expected annual inventory holding cost, denoted by $I H C$, and the expected annual rush ordering cost, denoted by $R O C$.

We start by studying the case where there is one shipment $(m=1)$, and then generalize results for the multiple shipments system $(m>1)$.

\subsection{Case of one shipment $(m=1)$}

The expected annual inventory holding cost $I H C$, is calculated using the following expression:

$I H C=h^{\text {batch }}\left(E S^{\text {batch }}+S S^{\text {batch }}\right)=h^{\text {batch }}\left(E S^{\text {batch }}+S^{\text {batch }}-\beta(T+D L T)\right)$

where $E S^{\text {batch }}$ represents the economy of scale inventory per time unit (in terms of batches). This term does not impact the optimization and can be calculated as presented in Appendix 2. $S^{\text {batch }}$ is equal to the sum of $S S^{\text {batch }}$ and the average component demand during $T+D L T$ expressed in terms of batch.

Calculating the exact expression of the expected annual rush ordering cost is not tractable analytically because of interrelationships among demand, regular delivery, and rush delivery as reported also by Tagaras and Vlachos (2001). In other words, if we want to know the probability of having a rush delivery during a time unit $t$, we calculate the probability $\mathrm{P}$ (on-hand inventory is less than component demand in $t$ ); nevertheless, the on-hand inventory in time unit $t$ depends on what happened (demand, regular delivery, rush delivery) before $t$ which makes the calculation intractable. Our approximate inventory model uses the following assumption: there is one possible rush delivery during $T$ (this approximation is evaluated in the next section). This simplifying assumption seems reasonable: since the unit rush ordering $\operatorname{cost} R$ would generally be higher than the 
unit inventory holding cost $h^{\text {batch }}$, the optimal expected number of rush orders during $T$ is expected to be low. The expression of $R O C$ is given by:

$$
R O C=R \times \frac{Y}{T} \times P\left(S^{\text {batch }}<D_{T+D L T}^{\text {batch }}\right)
$$

where $P\left(S^{\text {batch }}<D_{T+D L T}^{\text {batch }}\right)$ represents the probability of having one rush order during the review time interval $T . D_{T+D L T}^{\text {batch }}$ is demand (expressed in batches) in the time interval $T+D L T$ and is assumed to follow a Poisson distribution with mean $\beta(T+D L T) . \frac{Y}{T}$ represents the average number of inventory review cycles per year ( $Y$ is the number of days per year). $R O C$ is calculated in a way similar to the Cycle Service Level (CSL) approach used in literature.

The expected total cost per year, $T C$, is thus given by:

$$
T C\left(S^{\text {batch }}\right)=h^{\text {batch }}\left(E S^{\text {batch }}+S^{\text {batch }}-\beta(T+D L T)\right)+\frac{R Y}{T} P\left(S^{\text {batch }}<D_{T+D L T}^{\text {batch }}\right)
$$

The expected total cost $T C$ is a convex function (proof is given in Appendix 3). Therefore, $T C$ accepts a minimum $S^{\text {batch }^{*}} . T C$ is the sum of an increasing function $I H C\left(S^{\text {batch }}\right)$ and a decreasing function $\operatorname{ROC}\left(S^{\text {batch }}\right)$. When $S^{\text {batch }}$ increases by one unit (from $S^{\text {batch }}$ to $S^{\text {batch }}+1$ ), IHC increases by $h^{\text {batch }}$ and $R O C$ decreases by $\frac{R Y}{T}\left[P\left(S^{\text {batch }}+1<D_{T+D L T}^{\text {batch }}\right)-P\left(S^{\text {batch }}<D_{T+D L T}^{\text {batch }}\right)\right]$. The optimal value of $S^{\text {batch }}$ is attained when:

$$
\begin{aligned}
& h_{\text {batch }}+\frac{R Y}{T} \times\left[P\left(S^{\text {batch }}+1<D_{T+D L T}^{\text {batch }}\right)-P\left(S^{\text {batch }}<D_{T+D L T}^{\text {batch }}\right)\right] \geq 0 \\
& \stackrel{\text { yields }}{\longrightarrow} P\left(D_{T+D L T}^{\text {batch }} \leq S^{\text {batch }}+1\right)-P\left(D_{T+D L T}^{\text {batch }} \leq S^{\text {batch }}\right) \leq \frac{h^{\text {batch }} T}{R Y} \\
& \stackrel{\text { yields }}{\longrightarrow} \frac{e^{-\beta(T+D L T)} \times(\beta(T+D L T))^{S^{\text {batch }}+1}}{\left(S^{\text {batch }}+1\right) !} \leq \frac{h^{\text {batch }} T}{R Y} \\
& \stackrel{\text { yields }}{\longrightarrow} f\left(S^{\text {batch }}+1\right) \leq \frac{h^{\text {batch }} T}{R Y}, \text { which implies that: }
\end{aligned}
$$




$$
S^{\text {batch }^{*}}=f^{-1}\left(\frac{h^{\text {batch }} T}{R Y}\right)-1
$$

$f$ is the probability mass function of Poisson distribution (with mean $\beta(T+D L T)$ ) and $f^{-1}$ is its inverse function. Since the analytical expression of $f^{-1}$ is not available, numerical evaluation is used to calculate $S^{\text {batch* }}$. The optimal safety stock $S S^{\text {batch }}{ }^{*}$ is given by:

$$
S S^{\text {batch }^{*}}=S^{\text {batch }}-\beta(T+D L T)
$$

Equivalently, if inventory is expressed as units of component, the optimal safety stock $S S$ would be given by:

$$
S S^{*}=a\left(f^{-1}\left(\frac{a h T}{R Y}\right)-1-\beta(T+D L T)\right)
$$

\subsection{Case of multiple shipments $(m>1)$ :}

For the case of multiple shipments, the probability of using rush orders in a cycle $T$ becomes even more complex to calculate.

We use the same simplifying assumption as for the case $m=1$ : we assume that there is one possible rush order during time interval $T$. The second assumption we use is as follows: if a rush order is used, it is requested more probably after receiving the $m^{\text {th }}$ shipment during $T$ (it is intuitive that the highest probability to have a stock-out would be probably after the last shipment).

The multiple shipment model can be approximated by a single shipment model where shipment delivery lead time is equal to $G L T$ where $G L T$ is the time interval between sending a replenishment order to supplier and receiving the last shipment (the $m^{\text {th }}$ shipment). 


$$
G L T=D L T+\left\lceil(m-1) \times \frac{T}{m}\right\rceil
$$

As for the case of $m=1$, we formulate the model in terms of $S^{\text {batch }}$ and $S S^{\text {batch }}$. The expected total cost function to minimize is:

$$
T C\left(S^{\text {batch }}\right)=h^{\text {batch }}\left(E S^{\text {batch }}+S^{\text {batch }}-\beta(T+G L T)\right)+\frac{R Y}{T} \times P\left(S^{\text {batch }}<D_{T+G L T}^{\text {batch }}\right)
$$

Equation (8) is the same as equation (3) where $D L T$ is replaced by $G L T$. The optimal component safety stock $S S^{*}$ is calculated by the following expression (where $S^{\text {batch }^{*}}$ is calculated by equation (4)):

$$
\begin{aligned}
& S S^{*}=a\left(S^{\text {batch }^{*}}-\beta(T+G L T)\right) \\
& S S^{*}=a *\left(f^{-1}\left(\frac{a h T}{R Y}\right)-1-\beta(T+G L T)\right)
\end{aligned}
$$

$f$ is the probability mass function of Poisson distribution (with mean $\beta *(T+G L T)$ ).

\section{Numerical study}

In this section, we conduct a numerical study to evaluate the performance of the approximate model developed in section 4. Subsection 5.1 details parameters considered to compare the approximate model to an exact simulation model. Subsection 5.2 discusses the results and subsection 5.3 presents the application of the proposed approximate model to the case of an Alpha plant.

\subsection{Approaches and parameters}

We compare the optimal safety stock $S S^{*}$ given by the exact and approximate models in a large set of scenarios. Subscripts " $e$ " and " $a$ " are used to indicate the results given by the exact and approximate models respectively. 
For the case of approximate model, we use the expressions developed in section 4 to calculate $S S_{a}^{*}$ (given by equation (10)). For the case of exact model, a Discrete Event Simulation is developed in Matlab: for each scenario, a numerical enumeration of different safety stock values is used to determine the optimal value $S S_{e}^{*}$. For each safety stock value, events described in Figure 2 are run for 1 million time units. The warm-up period is set equal to 500 time units. The expected inventory holding cost $I H C_{e}$ is the cost of the average on-hand inventory over the considered time units (1 million-500), and the expected rush ordering cost $R O C_{e}$ is the average number of rush orders per year over the considered time units multiplied by the unit $\operatorname{cost} R$.

Ninety six scenarios are obtained from the combinations of the following parameters:

We consider 4 possible values for the average component demand $a \times \beta=\{1,5,20,100\}$, which represent low (1,5), medium (20) and high demand (100). Since it is the ratio $\frac{R}{h}$ which impacts the calculation of optimal safety stock, the annual unit holding cost $h$ is set equal to 1 for all scenarios. The unit rush ordering cost $R$ can take 4 values: 10, 50, 100 or 1000 . The review time interval $T$ can be equal to 1,5 or 10 . The delivery lead time $D L T$ is equal to 2 for all scenarios. 2 values for the number of shipments $m$ are taken: 1 and 5. The number of days per year, $Y$, is set equal to 240 days. The list of scenarios is 


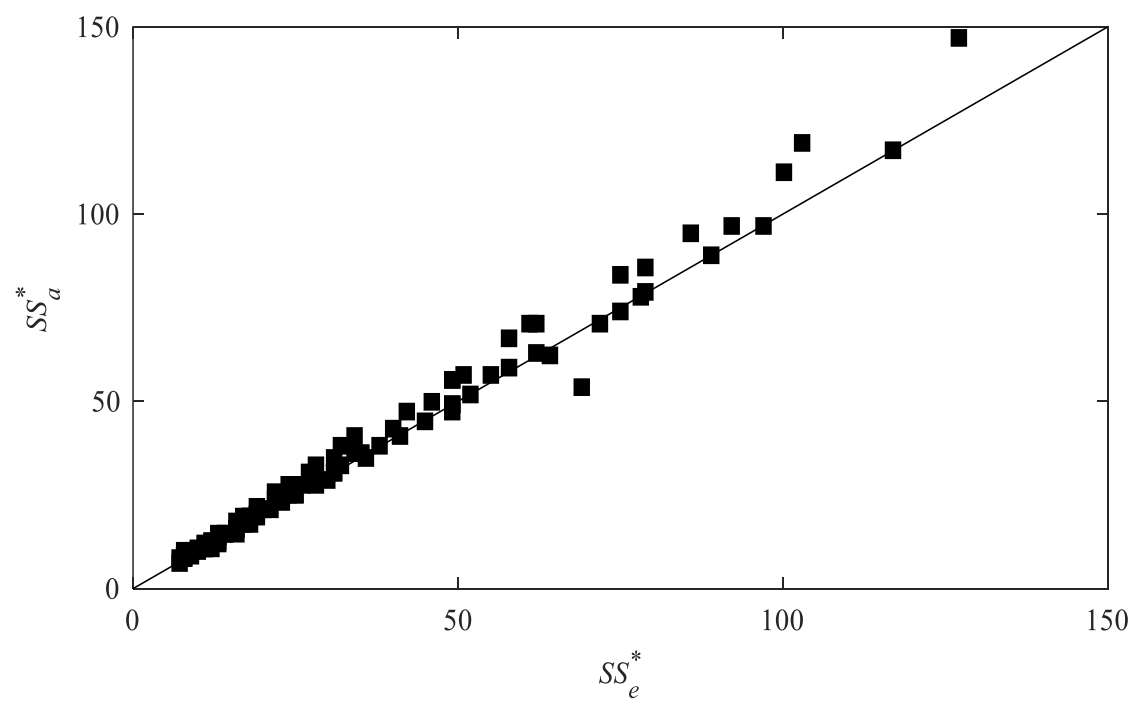

Figure 3. Values of $S S_{e}^{*}$ and $S S_{a}^{*}$

presented in Appendix 4. The comparison results for each scenario are presented in Appendix 5. We also give a summary of these results in Appendix 6: for each value of $a \times \beta, T, m$, and $R$, we calculate the average comparison results.

The assembly coefficient $a$ is equal to 1 for all scenarios. Indeed, from equation (8) it can be seen that the total cost $T C$ of a system with an assembly coefficient $a=1$ and a unit component inventory holding cost $h$ is equivalent to a system with an assembly coefficient $a^{\prime} \geq 1$ and a unit inventory holding cost $h^{\prime}=\frac{h}{a^{\prime}}$ (the two systems have the same value of $h^{\text {batch }}$ ). Hence, studying a system with an assembly coefficient different than 1 can be reduced to studying a system with an assembly coefficient equal to 1 (this equivalence is verified in the approximate and exact models). The demand of FGs for all scenarios follows a discrete time Poisson distribution with mean $\beta$.

\subsection{Approximate vs simulation models}

Figure 3 gives a scatter plot of the values of $S S_{e}^{*}$ and $S S_{a}^{*}$. It shows that the optimal safety stock estimation is good in the approximate model. More precisely, Figure 4 displays a 


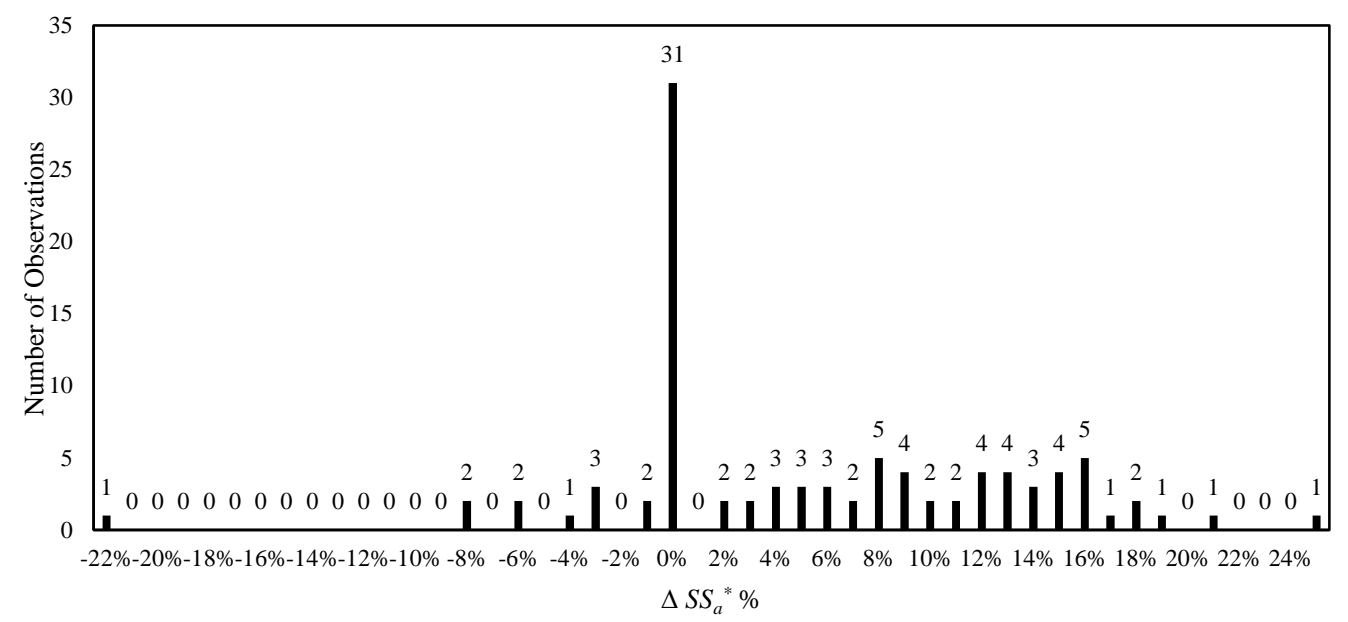

Figure 4. Histogram of $\Delta S S_{a}^{*} \%$

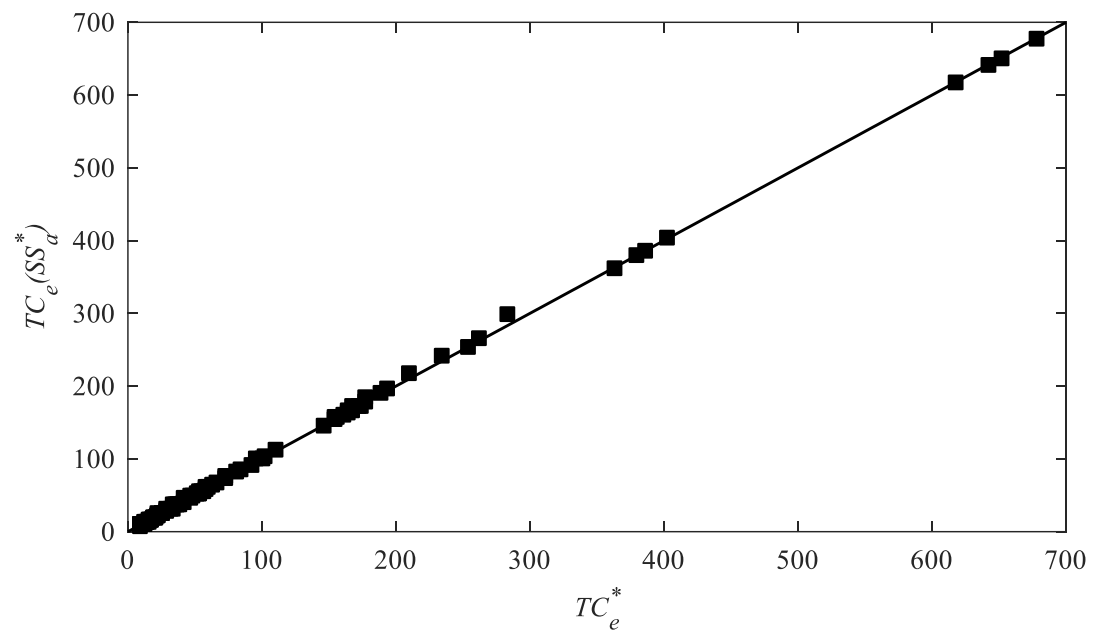

Figure 5. Values of $T C_{e}^{*}$ and $T C_{e}\left(S S_{a}^{*}\right)$

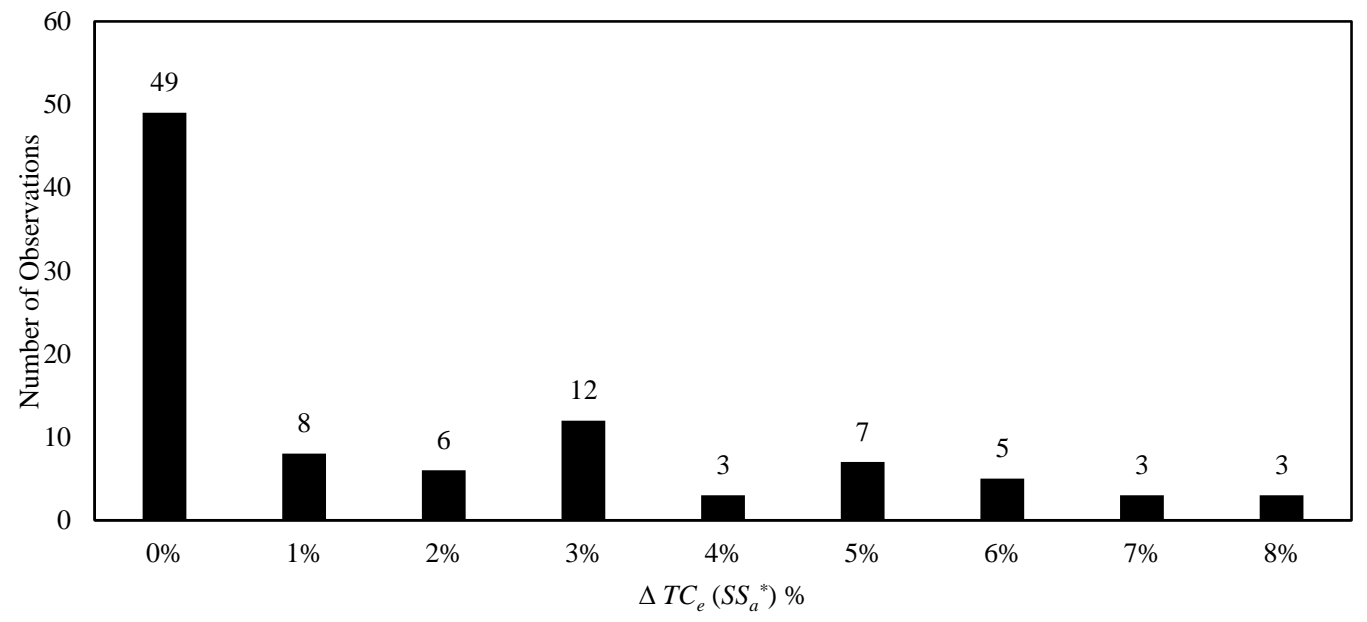

Figure 6. Variations of $\Delta T C_{e}\left(S S_{a}^{*}\right) \%$ 
Table 3. Evaluation of the approximate model for different values of $a \times \beta, T, m$, and $R$

\begin{tabular}{ccccc}
\hline & $\left|\Delta \boldsymbol{S S}_{\boldsymbol{a}}^{*}\right|$ & $\left|\Delta \boldsymbol{S} \boldsymbol{S}_{\boldsymbol{a}}^{*} \%\right|$ & $\left|\Delta \boldsymbol{T C}_{\boldsymbol{e}}\left(\boldsymbol{S S}_{\boldsymbol{a}}^{*}\right)\right|$ & $\left|\Delta \boldsymbol{T C}_{\boldsymbol{e}}\left(\boldsymbol{S S}_{\boldsymbol{a}}^{*}\right) \%\right|$ \\
\hline $\boldsymbol{a} \times \boldsymbol{\beta}=1$ & 0.67 & $6.4 \%$ & 0.27 & $1.9 \%$ \\
\hline $\boldsymbol{a} \times \boldsymbol{\beta}=5$ & 1.50 & $7.0 \%$ & 0.76 & $2.5 \%$ \\
\hline $\boldsymbol{a} \times \boldsymbol{\beta}=20$ & 2.79 & $7.2 \%$ & 1.23 & $1.8 \%$ \\
\hline $\boldsymbol{a} \times \boldsymbol{\beta}=100$ & 5.13 & $6.4 \%$ & 2.65 & $1.3 \%$ \\
\hline $\boldsymbol{m}=1$ & 0.46 & $1.9 \%$ & 0.09 & $0.2 \%$ \\
\hline $\boldsymbol{m}=5$ & 4.58 & $11.6 \%$ & 2.36 & $3.5 \%$ \\
\hline $\boldsymbol{T}=1$ & 2.44 & $8.9 \%$ & 1.17 & $2.3 \%$ \\
\hline $\boldsymbol{T}=5$ & 2.16 & $5.3 \%$ & 1.03 & $1.7 \%$ \\
\hline $\boldsymbol{T}=10$ & 2.97 & $6.0 \%$ & 1.48 & $1.7 \%$ \\
\hline $\boldsymbol{R}=10$ & 1.63 & $5.4 \%$ & 0.61 & $0.9 \%$ \\
\hline $\boldsymbol{R}=50$ & 1.96 & $5.8 \%$ & 0.72 & $1.6 \%$ \\
\hline $\boldsymbol{R}=100$ & 2.63 & $7.8 \%$ & 1.08 & $1.9 \%$ \\
\hline $\boldsymbol{R}=1000$ & 3.88 & $7.9 \%$ & 2.49 & $3.1 \%$ \\
\hline $\begin{array}{c}\text { All } \\
\text { scenarios }\end{array}$ & $\mathbf{2 . 5 2}$ & $\mathbf{6 . 7 \%}$ & $\mathbf{1 . 2 3}$ & $\mathbf{1 . 9 \%}$ \\
\hline & & & &
\end{tabular}

histogram of $S S_{a}^{*}$, expressed as a percentage of $S S_{e}^{*}$. This relative percentage is denoted by $\Delta S S_{a}^{*} \%$, where $\Delta S S_{a}^{*} \%=\frac{S S_{a}^{*}-S S_{e}^{*}}{S S_{e}^{*}}$. The calculated percentages are rounded and presented in Figure 4. The average percentage is 5.4\%, and the values range between $22 \%$ and $25 \%$. To evaluate the impact of the difference between $S S_{e}^{*}$ and $S S_{a}^{*}$, we compare the costs $T C_{e}^{*}$ (optimal total cost obtained by the exact model) and $T C_{e}\left(S S_{a}^{*}\right)$. If the difference between the two costs is small, we deduce that the difference between $S S_{e}^{*}$ and $S S_{a}^{*}$ has not a great impact and the estimation of the optimal safety stock by the approximate model would be good.

Figure 5 gives a scatter plot of the values of $T C_{e}^{*}$ and $T C_{e}\left(S S_{a}^{*}\right)$. Results show that values of $T C_{e}^{*}$ and $T C_{e}\left(S S_{a}^{*}\right)$ are close. Figure 6 displays a histogram of $T C_{e}\left(S S_{a}^{*}\right)$, expressed as a percentage of $T C_{e}^{*}$. This relative percentage is denoted by $\Delta T C_{e}\left(S S_{a}^{*}\right) \%$, where $\Delta T C_{e}\left(S S_{a}^{*}\right) \%=\frac{T C_{e}\left(S S_{a}^{*}\right)-T C_{e}^{*}}{T C_{e}^{*}}$. The average is $1.9 \%$ and values are between $0 \%$ and $8 \%$. It can be seen that the approximate model gives interesting results. Even if $\Delta S S_{a}^{*} \%$ ranges from $-22 \%$ to $25 \%$, the relative cost difference $\Delta T C_{e}\left(S S_{a}^{*}\right) \%$ does not 
vary much (from $0 \%$ to $8 \%$ ).

For different values of $a \times \beta, T, m$, and $R$, Table 3 presents the average of following indicators (absolute and relative differences): $\left|\Delta S S_{a}^{*}\right|=\left|S S_{a}^{*}-S S_{e}^{*}\right|,\left|\Delta S S_{a}^{*} \%\right|=\frac{\left|\Delta S S_{a}^{*}\right|}{S S_{e}^{*}}$, $\left|\Delta T C_{e}\left(S S_{a}^{*}\right)\right|=\left|T C_{e}\left(S S_{a}^{*}\right)-T C_{e}^{*}\right|$ and $\left|\Delta T C_{e}\left(S S_{a}^{*}\right) \%\right|=\frac{\left|\Delta T C_{e}\left(S S_{a}^{*}\right)\right|}{T C_{e}^{*}}$. We take the absolute value $|x|$ of these results because they may have negative values and the calculation of average in this case is biased. For instance, the first line represents the average results among all scenarios for which $a \times \beta=1$.

The average $\left|\Delta S S_{a}^{*}\right|$ among all scenarios is low (2.52). It increases with increasing $a \times \beta, m$, and $R$ and is not highly impacted by $T$. The average $\left|\Delta S S_{a}^{*} \%\right|$ of all scenarios is 6.7\%. It increases with increasing $m$ and $R$. The averages $\left|\Delta T C_{e}\left(S S_{a}^{*}\right)\right|$ is also low (1.23) and increases with increasing $a^{*} \beta, m$, and $R$. The average $\left|\Delta T C_{e}\left(S S_{a}^{*}\right) \%\right|$ is $1.9 \%$ and increases with increasing $m$ and $R$. These results show that the approximate model gives interesting results. The approximation is better in the case of $m=1\left(\left|\Delta S S_{a}^{*} \%\right|=1.9 \%\right)$ which enables to confirm that the simplifying assumption taken in section 4 is reasonable (there is one possible rush delivery during $T$ ). When $m=5$, the quality of the approximation of optimal safety stock is lower $\left(\left|\Delta S S_{a}^{*} \%\right|=11.6 \%\right)$. We think that this is probably due to the simplifying assumption of having one possible rush delivery during the last shipment. The increasing of $\left|\Delta S S_{a}^{*} \%\right|$ has not had a great impact on the cost $\left(\left|\Delta T C_{e}\left(S S_{a}^{*}\right) \%\right|=3.5 \%\right)$

\subsection{Managerial insights}

Based on the case of an Alpha plant situated in France, we compared our model for components' safety stocks calculation to the model currently used at Alpha (Alpha model). We started by a global comparison which takes into consideration all components 
in the plant. We calculated the total value of safety stock, $I H C, R O C$ and $T C$ pertaining to all components, for both models. We find that the models give approximately the same value of safety stock (the reduction percentages allow Alpha model to reduce safety stocks). IHC given by both models is also (approximately) the same. Despite this, $R O C$ values are different since the safety stock calculated by Alpha model is not optimal. In particular, the average probability of using rush ordering in Alpha model is more than ten times greater than the average probability obtained in our model (values are $3.31 \%$ and $0.31 \%$ respectively). As a result, our model allows to reduce $T C$ by $66 \%$, compared to

Alpha model. We also realised a more detailed comparison with respect to component families. We found that the average probability of using rush ordering is impacted by the average ratio $h / R$. For instance, the average ratios $h / R$ of two components families are respectively: $0.13 \%$ and $1.27 \%$. As a result, their average rush ordering probabilities are respectively $0.03 \%$ and $10 \%$. The impact of the different model parameters on $T C$ will be studied in the next section.

\section{Sensitivity analysis}

This section assesses the impact of parameters $a \times \beta, a, m, T$, and $R$. Figures 7 and 8 depict respectively the variations of the optimal safety stock $S S_{a}^{*}$ and the corresponding expected total cost $T C_{a}^{*}$ as a function of the assembly coefficient $a$, and the average component demand $a \times \beta$. For the same average component demand, $S S_{a}^{*}$ and $T C_{a}^{*}$ increase with increasing $a$. This result lies in the fact that the component demand variability increases with increasing values of assembly coefficient $a$ : increasing $a$ reduces the average FGs demand $\beta$ which increases FGs demand variability (the standard deviation of a Poisson

distribution is $\frac{1}{\sqrt{\beta}}$. For example, if the average component demand $a \times \beta=20, T=1, m=1$, $h=1$ and $R=100$ then increasing the assembly coefficient from 1 to 5 increases $S S_{a}^{*}$ from 


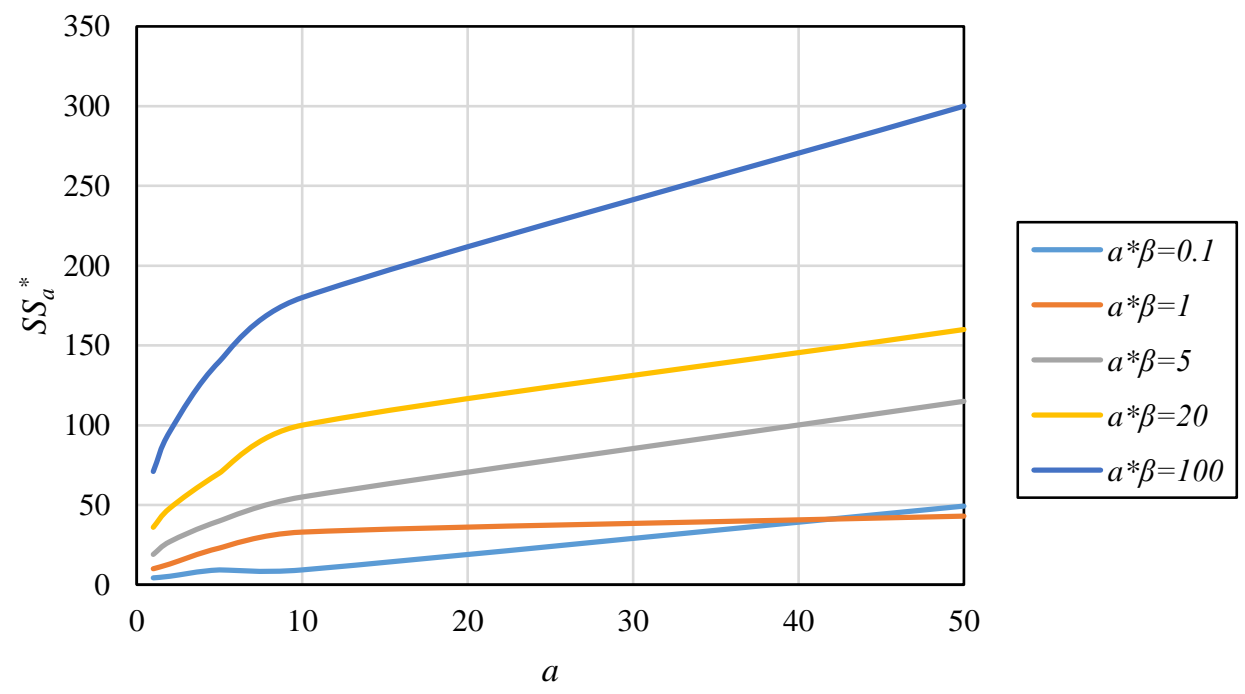

Figure 7. The variation of optimal safety stock $S S_{a}^{*}$ in function of assembly coefficient a and average component demand $a^{*} \beta(T=5, D L T=2, m=1, R=100)$

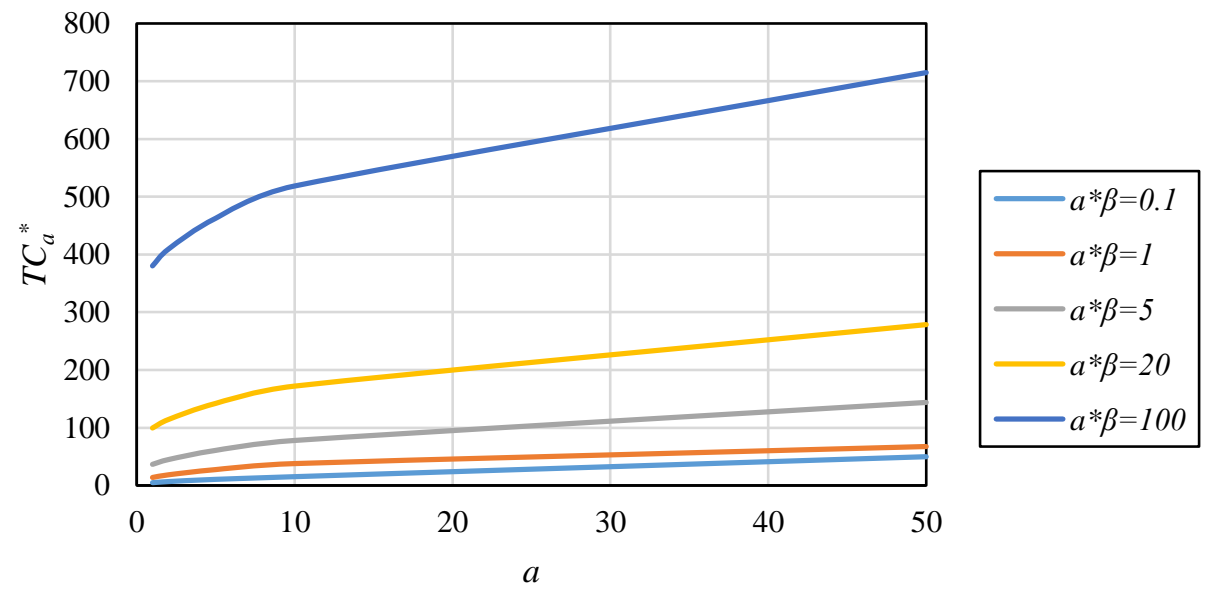

Figure 8 . The variation of optimal total cost $T C_{a}^{*}$ in function of assembly coefficient $a$ and average component demand $a * \beta(T=5, D L T=2, m=1, R=100)$

38 to 80 and $T C_{a}^{*}$ from 102.15 to $149 . S S_{a}^{*}$ and $T C_{a}^{*}$ increase also when the average component demand $a \times \beta$ increases for a given value of $a$. Because of the numerical integer optimization of the cost function, $S S_{a}^{*}$ is not strictly increasing when $a \times \beta=0.1$. 
Table 4. The impact of system parameters on $S S_{a}^{*}, T C_{a}^{*}, I H C_{a}^{*}$ and $R O C_{a}^{*}$

\begin{tabular}{ccccc}
\hline & $\boldsymbol{S S}_{\boldsymbol{a}}^{*}$ & $\boldsymbol{T} \boldsymbol{C}_{\boldsymbol{a}}^{*}$ & $\boldsymbol{I H C}_{\boldsymbol{a}}^{*}$ & $\boldsymbol{\boldsymbol { O O } _ { \boldsymbol { a } } ^ { * }}$ \\
\hline $\boldsymbol{a} \times \boldsymbol{\beta}=0.1$ & 17.75 & 20.05 & 17.99 & 2.07 \\
\hline $\boldsymbol{a} \times \boldsymbol{\beta}=1$ & 33.30 & 42.27 & 35.75 & 6.52 \\
\hline $\boldsymbol{a} \times \boldsymbol{\beta}=5$ & 60.80 & 85.67 & 73.03 & 12.64 \\
\hline $\boldsymbol{a} \times \boldsymbol{\beta}=20$ & 105.30 & 176.59 & 154.22 & 22.37 \\
\hline $\boldsymbol{a} \times \boldsymbol{\beta}=100$ & 187.51 & 484.91 & 432.09 & 52.82 \\
\hline $\boldsymbol{a}=1$ & 35.19 & 101.86 & 96.88 & 4.98 \\
\hline $\boldsymbol{a}=2$ & 46.99 & 116.37 & 108.67 & 7.70 \\
\hline $\boldsymbol{a}=5$ & 68.03 & 143.38 & 129.71 & 13.67 \\
\hline $\boldsymbol{a}=10$ & 89.95 & 171.73 & 151.63 & 20.10 \\
\hline $\boldsymbol{a}=50$ & 164.50 & 276.15 & 226.18 & 49.96 \\
\hline $\boldsymbol{m}=1$ & 72.02 & 198.37 & 182.36 & 16.01 \\
\hline $\boldsymbol{m}=2$ & 81.37 & 166.65 & 147.58 & 19.08 \\
\hline $\boldsymbol{m}=3$ & 83.28 & 154.82 & 134.77 & 20.05 \\
\hline $\boldsymbol{m}=4$ & 83.99 & 150.34 & 129.70 & 20.63 \\
\hline $\boldsymbol{m}=5$ & 83.99 & 139.30 & 118.67 & 20.63 \\
\hline $\boldsymbol{T}=1$ & 74.86 & 108.71 & 100.08 & 8.63 \\
\hline $\boldsymbol{T}=5$ & 81.11 & 144.72 & 127.34 & 17.38 \\
\hline $\boldsymbol{T}=10$ & 84.27 & 180.31 & 157.41 & 22.90 \\
\hline $\boldsymbol{T}=15$ & 83.49 & 213.85 & 185.63 & 28.22 \\
\hline $\boldsymbol{R}=10$ & 33.24 & 117.31 & 94.93 & 22.38 \\
\hline $\boldsymbol{R}=50$ & 71.42 & 154.98 & 133.10 & 21.87 \\
\hline $\boldsymbol{R}=100$ & 89.25 & 168.82 & 150.94 & 17.88 \\
\hline $\boldsymbol{R}=1000$ & 129.81 & 206.49 & 191.50 & 14.99 \\
\hline $\boldsymbol{2}$ & & & &
\end{tabular}

For a more comprehensive analysis, we consider 2000 scenarios obtained from other combinations of the following parameters: $a \times \beta=\{0.1,1,5,20,100\}, a=\{1,2,5,10,50\}$, $T=\{1,5,10,15\}, D L T=2, \quad m=\{1,2,3,4,5\}, R=\{10,50,100,1000\}$. Table 4 displays the average values of $S S_{a}^{*}, T C_{a}^{*}, I H C_{a}^{*}$ and $R O C_{a}^{*}$ for a subset of scenarios (for instance, the row $a \times \beta=0.1$ gives the average values of all scenarios where $a \times \beta=0.1$ ).

Similar to the conclusions of Figures 7 and 8, we find that $S S_{a}^{*}, T C_{a}^{*}, I H C_{a}^{*}$ and $R O C_{a}^{*}$ increase with increasing $a^{*} \beta$ and $a$. Increasing the number of shipments $m$ allows to reduce the economy of scale inventory and hence reduces $I H C_{a}^{*}$ and $T C_{a}^{*}$. On the other hand, increasing $m$ increases the risk of using rush deliveries and hence increases $R O C_{a}^{*}$. For that reason, $S S_{a}^{*}$ increases with increasing values of $m$. 
Table 5. Variation of average $S S_{a}^{*}$ in function of $a$ and $T$

\begin{tabular}{cccccc}
\hline & $\boldsymbol{a}=1$ & $\boldsymbol{a}=2$ & $\boldsymbol{a}=5$ & $\boldsymbol{a}=10$ & $\boldsymbol{a}=50$ \\
\hline $\boldsymbol{T}=1$ & 26.55 & 37.10 & 56.91 & 80.06 & 173.66 \\
\hline $\boldsymbol{T}=5$ & 34.05 & 46.28 & 68.60 & 91.30 & 165.30 \\
\hline $\boldsymbol{T}=10$ & 38.86 & 51.65 & 71.88 & 93.33 & 165.63 \\
\hline $\boldsymbol{T}=15$ & 41.31 & 52.91 & 74.71 & 95.11 & 153.41 \\
\hline
\end{tabular}

We find also that $T C_{a}^{*}, I H C_{a}^{*}$ and $R O C_{a}^{*}$ increase with increasing $T . S S_{a}^{*}$ increases with increasing $T$ but it is not monotonous (it decreases at $T=15$ ) probably because of integer optimization ( $S S_{a}^{*}$ is always multiple of $a$ ). To show the impact of integer optimization, it can be seen that $S S_{a}^{*}$ increases with increasing $T$, except for the case of $a=50$ (Table 5).

$S S_{a}^{*}$ increases with increasing $R$ because rush ordering costs become more expensive and increasing the safety stock will decrease them without impacting largely the inventory holding costs. $T C_{a}^{*}$ increases also with increasing values of $R$.

\section{Conclusions and perspectives}

In this paper, we study the calculation of optimal safety stocks in an ATO system which uses a periodic review policy $(T, S)$ to control inventory, with the possibility of using rush orders. The model presented is inspired from the context of Alpha, one of the largest auto parts makers in the world. Alpha plants use actually a safety stock calculation model that shows some limits. We compared the developed model to Alpha model (the one currently used at Alpha). We found that our model can lead to interesting cost reductions (up to $66 \%$ cost reduction). Even if both models use approximately the same safety stock value, our model is better in terms of total cost. The safety stock calculated by the proposed model law is also easier to interpret since it results from a trade-off between inventory holding and rush ordering costs. Based on results obtained, Alpha is actually considering the implementation of our model in the inventory management tool used by plant 
procurement managers.

In our model, we used a Cycle Service Level type approach in the calculation of optimal safety stock. An interesting approach would be the use of a Fill Rate approach where the rush order cost would depend on units of products requested. In terms of perspectives, it would be of interest also to consider the case of a variable rush order cost $R$ which depends on the quantity and the lead time of this order. In our paper, we assumed that each component demand follows a compound Poisson distribution. One interesting direction lies also in investigating real discrete probability distributions. Indeed, the technology of today's computers has enabled efficient operations with huge amounts of data. Consequently, processing of discrete data instead of applying approximate functions would provide more accurate results in practical applications.

Furthermore, in the studied system, we assumed that the supply of each component is independent from the other components, however some components can have the same supplier. If those components are in stock-out during the same time unit, then only one rush delivery would be used instead of using a rush delivery for each component. It is analytically complicated to calculate the optimal safety stocks in this case. To resolve this problem, we propose to use the expressions developed in our paper for this case also. After calculating the optimal safety stocks, the rush ordering costs need to be adjusted. We propose the use of the following approximation: the expected annual rush ordering cost for each component $i$ is equal to the same cost calculated by our model, divided by the number of components supplied by the supplier of component $i$.

\section{References}

Agrawal, Narendra, and Morris A. Cohen. 2001. 'Optimal Material Control in an Assembly System with Component Commonality'. Naval Research Logistics (NRL) 48 (5): 409-429. 
Akçay, Yalçin, and Susan H Xu. 2004. 'Joint Inventory Replenishment and Component Allocation Optimization in an Assemble-to-Order System'. Management Science 50 (1): 99-116.

Alvarez, E. M., Matthijs C. van der Heijden, and Willem HM Zijm. 2013. 'The Selective Use of Emergency Shipments for Service-Contract Differentiation'. International Journal of Production Economics 143 (2): 518-526.

Atan, Zümbül, Taher Ahmadi, Clara Stegehuis, Ton de Kok, and Ivo Adan. 2017. 'Assemble-to-Order Systems: A Review'. European Journal of Operational Research 261 (3): 866-879.

Axsäter, Sven. 2007. 'A Heuristic for Triggering Emergency Orders in an Inventory System'. European Journal of Operational Research 176 (2): 880-891.

Babai, M. Zied, Zied Jemai, and Yves Dallery. 2011. 'Analysis of Order-up-to-Level Inventory Systems with Compound Poisson Demand'. European Journal of Operational Research 210 (3): 552-558.

Benjaafar, Saif, and Mohsen ElHafsi. 2006. 'Production and Inventory Control of a Single Product Assemble-to-Order System with Multiple Customer Classes'. Management Science 52 (12): 1896-1912.

Boysen, Nils, Simon Emde, Michael Hoeck, and Markus Kauderer. 2015. 'Part Logistics in the Automotive Industry: Decision Problems, Literature Review and Research Agenda'. European Journal of Operational Research 242 (1): 107120.

Desmet, Bram, El-Houssaine Aghezzaf, and Hendrik Vanmaele. 2010. 'Safety Stock Optimisation in Two-Echelon Assembly Systems: Normal Approximation Models'. International Journal of Production Research 48 (19): 5767-5781.

Dhawan, Aayush, Samashivan Srinivasan, Prabina Rajib, and Bopaya Bidanda. 2009. 'Minimising Total Cost with Regular and Emergency Outsourcing Sources: A Neuro-Dynamic Programming Approach'. International Journal of Production Research 47 (20): 5811-5827.

ElHafsi, Mohsen, Herve Camus, and Etienne Craye. 2008. 'Optimal Control of a Nested-Multiple-Product Assemble-to-Order System'. International Journal of Production Research 46 (19): 5367-5392.

Elhafsi, Mohsen, Li Zhi, Herve Camus, and Etienne Craye. 2015. 'An Assemble-toOrder System with Product and Components Demand with Lost Sales'. International Journal of Production Research 53 (3): 718-735.

$\mathrm{Fu}, \mathrm{Ke}$, Vernon N. Hsu, and Chung-Yee Lee. 2011. 'Approximation Methods for the Analysis of a Multicomponent, Multiproduct Assemble-to-Order System'. Naval Research Logistics (NRL) 58 (7): 685-704.

Jalali, Hamed, and Inneke Van Nieuwenhuyse. 2015. 'Simulation Optimization in Inventory Replenishment: A Classification'. IIE Transactions 47 (11): 12171235.

Karaarslan, Ayşe Gönül, G. P. Kiesmüller, and A. G. De Kok. 2013. 'Analysis of an Assemble-to-Order System with Different Review Periods'. International Journal of Production Economics 143 (2): 335-341.

Mardan, Ehsan, Mohsen Sadegh Amalnik, and Masoud Rabbani. 2015. 'An Integrated Emergency Ordering and Production Planning Optimization Model with Demand and Yield Uncertainty'. International Journal of Production Research 53 (20): 6023-6039.

Moinzadeh, Kamran, and Charles P. Schmidt. 1991. 'An (S- 1, S) Inventory System with Emergency Orders'. Operations Research 39 (2): 308-321. 
Smith, Stephen A. 1977. 'Optimal Inventories for an (S- 1, S) System with No Backorders'. Management Science 23 (5): 522-528.

Song, Jing-Sheng, and Paul Zipkin. 2003. 'Supply Chain Operations: Assemble-toOrder Systems'. Handbooks in Operations Research and Management Science 11: 561-596.

Tagaras, George, and Dimitrios Vlachos. 2001. 'A Periodic Review Inventory System with Emergency Replenishments'. Management Science 47 (3): 415-429.

Vlachos, Dimitrios, and George Tagaras. 2001. 'An Inventory System with Two Supply Modes and Capacity Constraints'. International Journal of Production Economics 72 (1): 41-58.

Woerner, Stefan, Marco Laumanns, and Stephan M. Wagner. 2017. 'Joint Optimisation of Capacity and Safety Stock Allocation'. International Journal of Production Research, 1-17.

Xiao, Yongbo, Jian Chen, and Chung-Yee Lee. 2010. 'Optimal Decisions for Assemble-to-Order Systems with Uncertain Assembly Capacity'. International Journal of Production Economics 123 (1): 155-65.

Zhao, Yao. 2009. 'Analysis and Evaluation of an Assemble-to-Order System with Batch Ordering Policy and Compound Poisson Demand'. European Journal of Operational Research 198 (3): 800-809.

Zheng, Meimei, Yan Shu, and Kan Wu. 2015. 'On Optimal Emergency Orders with Updated Demand Forecast and Limited Supply'. International Journal of Production Research 53 (12): 3692-3719. 


\section{Appendix 1: Table of notations}

Notation

\begin{tabular}{cl}
\hline$n_{c}$ & number of components \\
\hline$n_{f}$ & number of finished goods \\
\hline$a$ & assembly coefficient \\
\hline$\beta$ & mean arrival rate of customer orders for a FG \\
\hline$a \times \beta$ & mean arrival rate of customer orders for a component \\
\hline$T$ & review time interval \\
\hline$S$ & order up-to level expressed as units of component \\
\hline$D L T$ & delivery lead time \\
\hline$m$ & number of shipments during $T$ \\
\hline$R S$ & unit rush order cost \\
\hline$S^{b a t c h}$ & safety stock expressed as units of component \\
\hline$S S^{b a t c h}$ & order up-to level expressed as batches \\
\hline$T C$ & safety stock expressed as batches \\
\hline$I H C$ & expected total cost per year \\
\hline$R O C$ & expected annual inventory holding cost \\
\hline$h$ & expected annual rush ordering cost \\
\hline$h^{\text {batch }}$ & inventory holding cost per unit per year \\
\hline$D_{T+D L T}^{\text {batch }}$ & inventory holding cost per batch per year \\
\hline$Y$ & demand (expressed in batches) in the time interval $T+D L T$ \\
\hline$G L T$ & number of days per year \\
\hline & time interval between sending a replenishment order to \\
\hline supplier and receiving the ${ }^{\text {th }}$ shipment)
\end{tabular}

\section{Appendix 2: Calculation of the economy of scale term ES $S^{\text {batch }}$}

This appendix explains how the term $E S^{\text {batch }}$ appearing in equations (3) and (8) is calculated. In a continuous time model, the term $E S^{\text {batch }}$ would be equal to $\frac{\beta * T}{2}$. In a discrete time model, the calculation is different. We use the algorithm below to calculate $E S^{\text {batch }}$ (this algorithm can be used for any nonnegative value of $m$ ). This algorithm calculates the average on-hand inventory per day. We remind that $E S^{\text {batch }}$ has not an impact on the optimization of component safety stock. This term is used to calculate the total cost. 


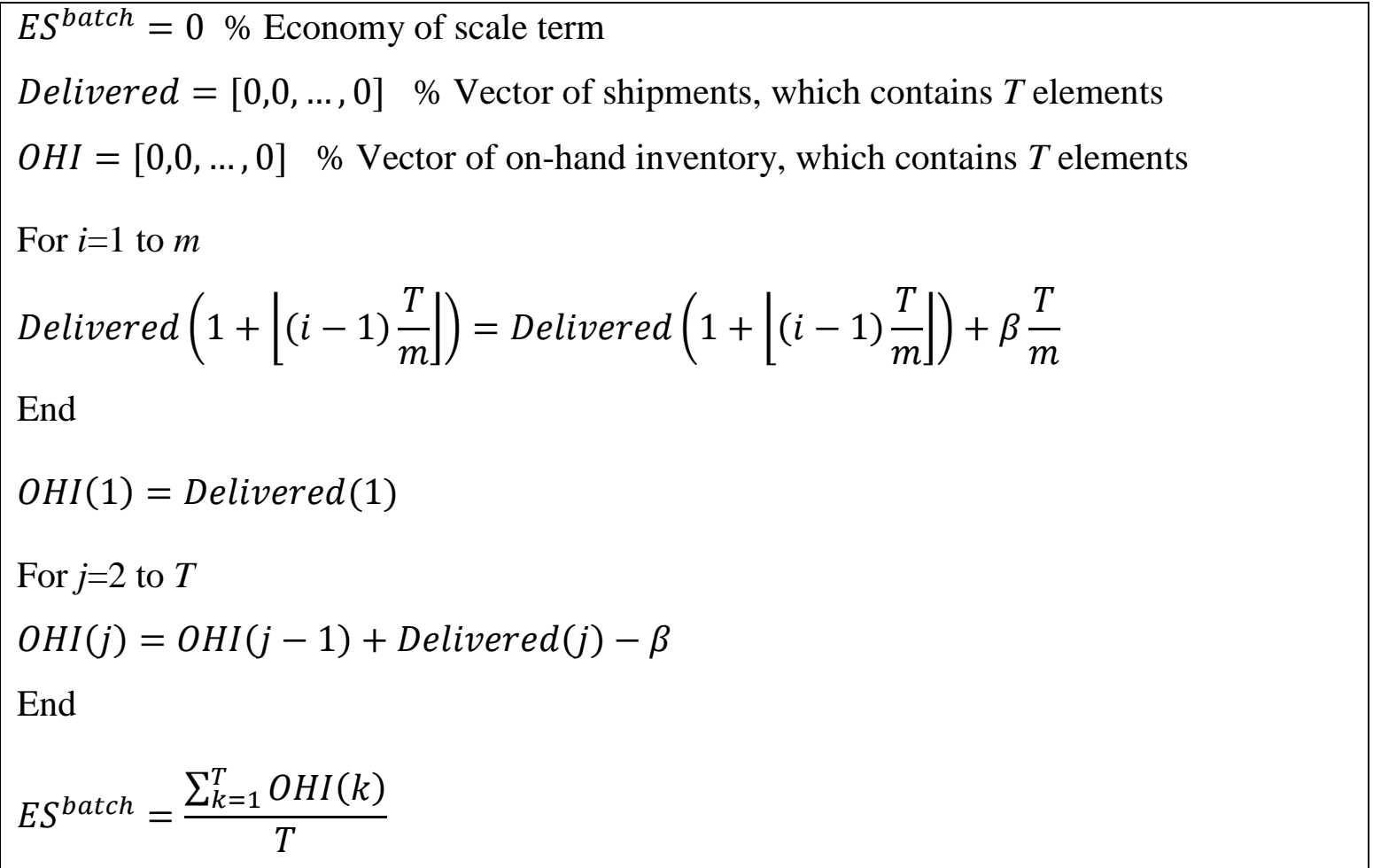

Algorithm 1. Calculation of the economy of scale term $E S^{\text {batch }}$

\section{Appendix 3: Proof of convexity}

To study the convexity of the expected total costs function $T C\left(S^{\text {batch }}\right)$, we assume that $S^{\text {batch }}$ is a positive real which can take no integer values. We know also that $S^{\text {batch }} \geq$ $\beta(T+D L T)$.

From equation (4), we have:

$$
T C\left(S^{\text {batch }}\right)=h^{\text {batch }}\left(E S^{\text {batch }}+S^{\text {batch }}-\beta(T+D L T)\right)+\frac{R Y}{T} \times\left(1-F\left(S^{\text {batch }}\right)\right)
$$

$F($.$) and f($.$) are the cumulative distribution function and the probability distribution$ function of Poisson, respectively. We put $x=\beta(T+D L T)$. We use the continuous version of Poisson probability distribution function where:

$$
f\left(S^{\text {batch }}\right)=\frac{e^{-x} x^{S^{b a t c h}}}{S^{b a t c h} !}=\frac{e^{-x} x^{S^{b a t c h}}}{\Gamma\left(S^{b a t c h}+1\right)}
$$

In fact, we replaced the factorial term $S^{\text {batch }}$ ! by the continuous function $\Gamma\left(S^{\text {batch }}+1\right)$ in order to calculate the derivatives where $\Gamma()$ is the Gamma function.

The first and second conditions of convexity yield to:

\section{- First condition of convexity:}




$$
\begin{gathered}
\frac{d T C}{d S^{\text {batch }}}=h^{\text {batch }}-\frac{R Y}{T} f\left(S^{\text {batch }}\right)=0 \\
S^{\text {batch }}=f^{-1}\left(\frac{h^{\text {batch }} T}{R Y}\right)
\end{gathered}
$$

Where $S^{\text {batch }}{ }^{*}$ is the optimal solution when $S^{\text {batch }}$ is a non-negative real (the value of $S^{\text {batch }}{ }^{*}$ in the case of a non-integer $S^{\text {batch }}$ may be different).

- Second condition of convexity:

$$
\frac{d^{2} T C}{d S^{b^{b a t c h}}{ }^{2}}=-\frac{R Y}{T}\left(\frac{e^{-x} x^{S^{\text {batch }}}}{\Gamma\left(S^{\text {batch }}+1\right)}\right)^{\prime}
$$

We have $\left(\frac{e^{-x} x^{S^{b a t c h}}}{\Gamma\left(S^{b a t c h}+1\right)}\right)^{\prime}=\frac{e^{-x} \ln (x) x^{S^{b a t c h}} \Gamma\left(S^{b a t c h}+1\right)-\Gamma\left(S^{b a t c h}+1\right)^{\prime} e^{-x} x^{s^{b a t c h}}}{\left(\Gamma\left(s^{b a t c h}+1\right)\right)^{2}}$

Knowing that: $\Gamma^{\prime}\left(S^{\text {batch }}+1\right)=\Gamma\left(S^{\text {batch }}+1\right) \psi\left(S^{\text {batch }}+1\right)$ where $\psi()$ is the Digamma function. We have:

$$
\begin{aligned}
& \left(\frac{e^{-x} x^{S^{b a t c h}}}{\Gamma\left(S^{\text {batch }}+1\right)}\right)^{\prime}=\frac{e^{-x} \ln (x) x^{S^{\text {batch }}} \Gamma\left(S^{\text {batch }}+1\right)-\Gamma\left(S^{\text {batch }}+1\right) \psi\left(S^{\text {batch }}+1\right) e^{-x} x^{S^{\text {batch }}}}{\left(\Gamma\left(S^{\text {batch }}+1\right)\right)^{2}} \\
& \left(\frac{e^{-x} x^{S^{b a t c h}}}{\Gamma\left(S^{b a t c h}+1\right)}\right)^{\prime}=\frac{e^{-x} x^{S^{b a t c h}} \Gamma\left(S^{\text {batch }}+1\right)}{\left(\Gamma\left(S^{b a t c h}+1\right)\right)^{2}}\left(\ln (x)-\psi\left(S^{\text {batch }}+1\right)\right)
\end{aligned}
$$

The Gamma function is always positive.

The Digamma function is an increasing function, i.e., $\psi\left(S^{\text {batch }}+1\right) \geq \psi(x+1)$ $\forall S^{\text {batch }} \geq x$

On the other hand, we can verify numerically, that $(x+1) \geq \ln (x) \forall x \geq 0$. Consequently, we can say that: $\psi\left(S^{\text {batch }}+1\right) \geq \ln (x)$.

As a result

$$
\frac{d^{2} T C}{d S^{\text {batch }^{2}}} \geq 0
$$

Hence the function $T C$ is convex in function of $S^{\text {batch }}$. 
Appendix 4: List of scenarios considered in the comparison between the approximate and exact models

\begin{tabular}{|c|c|c|c|c|c|c|c|c|}
\hline Scenario number & $a \times \beta$ & $a$ & $\boldsymbol{\beta}$ & $T$ & $D L T$ & $m$ & $\boldsymbol{h}$ & $R$ \\
\hline 1 & 1 & 1 & 1 & 1 & 2 & 1 & 1 & 10 \\
\hline 2 & 1 & 1 & 1 & 1 & 2 & 1 & 1 & 50 \\
\hline 3 & 1 & 1 & 1 & 1 & 2 & 1 & 1 & 100 \\
\hline 4 & 1 & 1 & 1 & 1 & 2 & 1 & 1 & 1000 \\
\hline 5 & 1 & 1 & 1 & 1 & 2 & 5 & 1 & 10 \\
\hline 6 & 1 & 1 & 1 & 1 & 2 & 5 & 1 & 50 \\
\hline 7 & 1 & 1 & 1 & 1 & 2 & 5 & 1 & 100 \\
\hline 8 & 1 & 1 & 1 & 1 & 2 & 5 & 1 & 1000 \\
\hline 9 & 1 & 1 & 1 & 5 & 2 & 1 & 1 & 10 \\
\hline 10 & 1 & 1 & 1 & 5 & 2 & 1 & 1 & 50 \\
\hline 11 & 1 & 1 & 1 & 5 & 2 & 1 & 1 & 100 \\
\hline 12 & 1 & 1 & 1 & 5 & 2 & 1 & 1 & 1000 \\
\hline 13 & 1 & 1 & 1 & 5 & 2 & 5 & 1 & 10 \\
\hline 14 & 1 & 1 & 1 & 5 & 2 & 5 & 1 & 50 \\
\hline 15 & 1 & 1 & 1 & 5 & 2 & 5 & 1 & 100 \\
\hline 16 & 1 & 1 & 1 & 5 & 2 & 5 & 1 & 1000 \\
\hline 17 & 1 & 1 & 1 & 10 & 2 & 1 & 1 & 10 \\
\hline 18 & 1 & 1 & 1 & 10 & 2 & 1 & 1 & 50 \\
\hline 19 & 1 & 1 & 1 & 10 & 2 & 1 & 1 & 100 \\
\hline 20 & 1 & 1 & 1 & 10 & 2 & 1 & 1 & 1000 \\
\hline 21 & 1 & 1 & 1 & 10 & 2 & 5 & 1 & 10 \\
\hline 22 & 1 & 1 & 1 & 10 & 2 & 5 & 1 & 50 \\
\hline 23 & 1 & 1 & 1 & 10 & 2 & 5 & 1 & 100 \\
\hline 24 & 1 & 1 & 1 & 10 & 2 & 5 & 1 & 1000 \\
\hline 25 & 5 & 1 & 5 & 1 & 2 & 1 & 1 & 10 \\
\hline 26 & 5 & 1 & 5 & 1 & 2 & 1 & 1 & 50 \\
\hline 27 & 5 & 1 & 5 & 1 & 2 & 1 & 1 & 100 \\
\hline 28 & 5 & 1 & 5 & 1 & 2 & 1 & 1 & 1000 \\
\hline 29 & 5 & 1 & 5 & 1 & 2 & 5 & 1 & 10 \\
\hline 30 & 5 & 1 & 5 & 1 & 2 & 5 & 1 & 50 \\
\hline 31 & 5 & 1 & 5 & 1 & 2 & 5 & 1 & 100 \\
\hline 32 & 5 & 1 & 5 & 1 & 2 & 5 & 1 & 1000 \\
\hline 33 & 5 & 1 & 5 & 5 & 2 & 1 & 1 & 10 \\
\hline 34 & 5 & 1 & 5 & 5 & 2 & 1 & 1 & 50 \\
\hline 35 & 5 & 1 & 5 & 5 & 2 & 1 & 1 & 100 \\
\hline 36 & 5 & 1 & 5 & 5 & 2 & 1 & 1 & 1000 \\
\hline 37 & 5 & 1 & 5 & 5 & 2 & 5 & 1 & 10 \\
\hline 38 & 5 & 1 & 5 & 5 & 2 & 5 & 1 & 50 \\
\hline 39 & 5 & 1 & 5 & 5 & 2 & 5 & 1 & 100 \\
\hline 40 & 5 & 1 & 5 & 5 & 2 & 5 & 1 & 1000 \\
\hline 41 & 5 & 1 & 5 & 10 & 2 & 1 & 1 & 10 \\
\hline 42 & 5 & 1 & 5 & 10 & 2 & 1 & 1 & 50 \\
\hline 43 & 5 & 1 & 5 & 10 & 2 & 1 & 1 & 100 \\
\hline 44 & 5 & 1 & 5 & 10 & 2 & 1 & 1 & 1000 \\
\hline 45 & 5 & 1 & 5 & 10 & 2 & 5 & 1 & 10 \\
\hline 46 & 5 & 1 & 5 & 10 & 2 & 5 & 1 & 50 \\
\hline 47 & 5 & 1 & 5 & 10 & 2 & 5 & 1 & 100 \\
\hline 48 & 5 & 1 & 5 & 10 & 2 & 5 & 1 & 1000 \\
\hline 49 & 20 & 1 & 20 & 1 & 2 & 1 & 1 & 10 \\
\hline 50 & 20 & 1 & 20 & 1 & 2 & 1 & 1 & 50 \\
\hline
\end{tabular}




\begin{tabular}{|c|c|c|c|c|c|c|c|c|}
\hline 51 & 20 & 1 & 20 & 1 & 2 & 1 & 1 & 100 \\
\hline 52 & 20 & 1 & 20 & 1 & 2 & 1 & 1 & 1000 \\
\hline 53 & 20 & 1 & 20 & 1 & 2 & 5 & 1 & 10 \\
\hline 54 & 20 & 1 & 20 & 1 & 2 & 5 & 1 & 50 \\
\hline 55 & 20 & 1 & 20 & 1 & 2 & 5 & 1 & 100 \\
\hline 56 & 20 & 1 & 20 & 1 & 2 & 5 & 1 & 1000 \\
\hline 57 & 20 & 1 & 20 & 5 & 2 & 1 & 1 & 10 \\
\hline 58 & 20 & 1 & 20 & 5 & 2 & 1 & 1 & 50 \\
\hline 59 & 20 & 1 & 20 & 5 & 2 & 1 & 1 & 100 \\
\hline 60 & 20 & 1 & 20 & 5 & 2 & 1 & 1 & 1000 \\
\hline 61 & 20 & 1 & 20 & 5 & 2 & 5 & 1 & 10 \\
\hline 62 & 20 & 1 & 20 & 5 & 2 & 5 & 1 & 50 \\
\hline 63 & 20 & 1 & 20 & 5 & 2 & 5 & 1 & 100 \\
\hline 64 & 20 & 1 & 20 & 5 & 2 & 5 & 1 & 1000 \\
\hline 65 & 20 & 1 & 20 & 10 & 2 & 1 & 1 & 10 \\
\hline 66 & 20 & 1 & 20 & 10 & 2 & 1 & 1 & 50 \\
\hline 67 & 20 & 1 & 20 & 10 & 2 & 1 & 1 & 100 \\
\hline 68 & 20 & 1 & 20 & 10 & 2 & 1 & 1 & 1000 \\
\hline 69 & 20 & 1 & 20 & 10 & 2 & 5 & 1 & 10 \\
\hline 70 & 20 & 1 & 20 & 10 & 2 & 5 & 1 & 50 \\
\hline 71 & 20 & 1 & 20 & 10 & 2 & 5 & 1 & 100 \\
\hline 72 & 20 & 1 & 20 & 10 & 2 & 5 & 1 & 1000 \\
\hline 73 & 100 & 1 & 100 & 1 & 2 & 1 & 1 & 10 \\
\hline 74 & 100 & 1 & 100 & 1 & 2 & 1 & 1 & 50 \\
\hline 75 & 100 & 1 & 100 & 1 & 2 & 1 & 1 & 100 \\
\hline 76 & 100 & 1 & 100 & 1 & 2 & 1 & 1 & 1000 \\
\hline 77 & 100 & 1 & 100 & 1 & 2 & 5 & 1 & 10 \\
\hline 78 & 100 & 1 & 100 & 1 & 2 & 5 & 1 & 50 \\
\hline 79 & 100 & 1 & 100 & 1 & 2 & 5 & 1 & 100 \\
\hline 80 & 100 & 1 & 100 & 1 & 2 & 5 & 1 & 1000 \\
\hline 81 & 100 & 1 & 100 & 5 & 2 & 1 & 1 & 10 \\
\hline 82 & 100 & 1 & 100 & 5 & 2 & 1 & 1 & 50 \\
\hline 83 & 100 & 1 & 100 & 5 & 2 & 1 & 1 & 100 \\
\hline 84 & 100 & 1 & 100 & 5 & 2 & 1 & 1 & 1000 \\
\hline 85 & 100 & 1 & 100 & 5 & 2 & 5 & 1 & 10 \\
\hline 86 & 100 & 1 & 100 & 5 & 2 & 5 & 1 & 50 \\
\hline 87 & 100 & 1 & 100 & 5 & 2 & 5 & 1 & 100 \\
\hline 88 & 100 & 1 & 100 & 5 & 2 & 5 & 1 & 1000 \\
\hline 89 & 100 & 1 & 100 & 10 & 2 & 1 & 1 & 10 \\
\hline 90 & 100 & 1 & 100 & 10 & 2 & 1 & 1 & 50 \\
\hline 91 & 100 & 1 & 100 & 10 & 2 & 1 & 1 & 100 \\
\hline 92 & 100 & 1 & 100 & 10 & 2 & 1 & 1 & 1000 \\
\hline 93 & 100 & 1 & 100 & 10 & 2 & 5 & 1 & 10 \\
\hline 94 & 100 & 1 & 100 & 10 & 2 & 5 & 1 & 50 \\
\hline 95 & 100 & 1 & 100 & 10 & 2 & 5 & 1 & 100 \\
\hline 96 & 100 & 1 & 100 & 10 & 2 & 5 & 1 & 1000 \\
\hline
\end{tabular}


Appendix 5: Results of comparison between the approximate and exact models

\begin{tabular}{|c|c|c|c|c|c|c|c|c|c|c|c|}
\hline \multirow[b]{2}{*}{$\begin{array}{l}\text { Scenario } \\
\text { number }\end{array}$} & \multicolumn{4}{|c|}{ Exact model (Optimal) } & \multicolumn{4}{|c|}{ Approximate model } & \multicolumn{3}{|c|}{ Exact model with $S S_{a}^{*}$} \\
\hline & $S S_{e}^{*}$ & $T C_{e}^{*}$ & $I H C_{e}^{*}$ & $\boldsymbol{R O C} C_{e}^{*}$ & $S S_{a}^{*}$ & $T C_{a}^{*}$ & $I H C_{a}^{*}$ & $\operatorname{ROC}_{a}^{*}$ & $T C_{e}^{*}\left(S S_{a}^{*}\right)$ & $I H C_{e}^{*}\left(S S_{a}^{*}\right)$ & $\operatorname{ROC}_{e}^{*}\left(S S_{a}^{*}\right)$ \\
\hline 1 & 7 & 8.61 & 8.00 & 0.61 & 7 & 8.70 & 8.00 & 0.70 & 8.61 & 8.00 & 0.61 \\
\hline 2 & 8 & 9.76 & 9.00 & 0.76 & 8 & 9.86 & 9.00 & 0.86 & 9.76 & 9.00 & 0.76 \\
\hline 3 & 8 & 10.51 & 9.00 & 1.51 & 9 & 10.39 & 10.00 & 0.39 & 10.53 & 10.00 & 0.53 \\
\hline 4 & 10 & 11.96 & 11.00 & 0.96 & 10 & 11.82 & 11.00 & 0.82 & 11.96 & 11.00 & 0.96 \\
\hline 5 & 7 & 8.61 & 8.00 & 0.61 & 8 & 9.66 & 9.00 & 0.66 & 9.15 & 9.00 & 0.15 \\
\hline 6 & 8 & 9.76 & 9.00 & 0.76 & 9 & 10.92 & 10.00 & 0.92 & 10.27 & 10.00 & 0.26 \\
\hline 7 & 8 & 10.51 & 9.00 & 1.51 & 10 & 11.48 & 11.00 & 0.48 & 11.10 & 11.00 & 0.10 \\
\hline 8 & 10 & 11.96 & 11.00 & 0.96 & 11 & 13.17 & 12.00 & 1.17 & 12.00 & 12.00 & 0.00 \\
\hline 9 & 8 & 12.35 & 11.01 & 1.34 & 8 & 12.16 & 11.00 & 1.16 & 12.35 & 11.01 & 1.34 \\
\hline 10 & 10 & 14.03 & 13.01 & 1.02 & 10 & 13.87 & 13.00 & 0.87 & 14.03 & 13.01 & 1.02 \\
\hline 11 & 11 & 14.97 & 14.00 & 0.96 & 11 & 14.62 & 14.00 & 0.62 & 14.97 & 14.00 & 0.96 \\
\hline 12 & 13 & 16.96 & 16.00 & 0.96 & 13 & 16.70 & 16.00 & 0.70 & 16.96 & 16.00 & 0.96 \\
\hline 13 & 9 & 11.22 & 10.01 & 1.22 & 10 & 12.08 & 11.00 & 1.08 & 11.49 & 11.01 & 0.48 \\
\hline 14 & 11 & 13.02 & 12.01 & 1.01 & 12 & 14.11 & 13.00 & 1.11 & 13.41 & 13.01 & 0.41 \\
\hline 15 & 12 & 13.82 & 13.01 & 0.82 & 13 & 14.95 & 14.00 & 0.95 & 14.25 & 14.01 & 0.24 \\
\hline 16 & 14 & 15.49 & 15.01 & 0.48 & 15 & 17.57 & 16.00 & 1.57 & 16.01 & 16.01 & 0.00 \\
\hline 17 & 9 & 16.41 & 14.52 & 1.89 & 9 & 15.96 & 14.50 & 1.46 & 16.41 & 14.52 & 1.89 \\
\hline 18 & 12 & 18.71 & 17.51 & 1.20 & 11 & 18.27 & 16.50 & 1.77 & 18.95 & 16.51 & 2.44 \\
\hline 19 & 13 & 19.81 & 18.51 & 1.30 & 12 & 19.15 & 17.50 & 1.65 & 19.91 & 17.51 & 2.40 \\
\hline 20 & 16 & 22.47 & 21.51 & 0.96 & 15 & 21.84 & 20.50 & 1.34 & 23.63 & 20.51 & 3.12 \\
\hline 21 & 11 & 13.64 & 12.52 & 1.12 & 11 & 14.44 & 12.50 & 1.94 & 13.64 & 12.52 & 1.12 \\
\hline 22 & 13 & 15.72 & 14.52 & 1.20 & 14 & 17.29 & 15.50 & 1.79 & 16.20 & 15.51 & 0.68 \\
\hline 23 & 14 & 16.88 & 15.51 & 1.37 & 15 & 18.43 & 16.50 & 1.93 & 17.02 & 16.51 & 0.50 \\
\hline 24 & 18 & 19.51 & 19.51 & 0.00 & 19 & 21.78 & 20.50 & 1.28 & 20.51 & 20.51 & 0.00 \\
\hline 25 & 13 & 19.91 & 18.00 & 1.90 & 14 & 20.00 & 19.00 & 1.00 & 19.97 & 19.00 & 0.97 \\
\hline 26 & 16 & 21.88 & 21.00 & 0.88 & 16 & 22.08 & 21.00 & 1.08 & 21.88 & 21.00 & 0.88 \\
\hline 27 & 17 & 22.67 & 22.00 & 0.67 & 17 & 22.96 & 22.00 & 0.96 & 22.67 & 22.00 & 0.67 \\
\hline 28 & 19 & 25.20 & 24.00 & 1.20 & 20 & 25.72 & 25.00 & 0.72 & 25.72 & 25.00 & 0.72 \\
\hline 29 & 13 & 19.91 & 18.00 & 1.90 & 15 & 21.93 & 20.00 & 1.93 & 20.44 & 20.00 & 0.44 \\
\hline 30 & 16 & 21.88 & 21.00 & 0.88 & 18 & 24.31 & 23.00 & 1.31 & 23.16 & 23.00 & 0.16 \\
\hline 31 & 17 & 22.67 & 22.00 & 0.67 & 19 & 25.28 & 24.00 & 1.28 & 24.12 & 24.00 & 0.12 \\
\hline 32 & 19 & 25.20 & 24.00 & 1.20 & 22 & 28.30 & 27.00 & 1.30 & 27.00 & 27.00 & 0.00 \\
\hline
\end{tabular}




\begin{tabular}{|c|c|c|c|c|c|c|c|c|c|c|c|}
\hline 33 & 16 & 32.96 & 31.01 & 1.95 & 16 & 33.05 & 31.00 & 2.05 & 32.96 & 31.01 & 1.95 \\
\hline 34 & 19 & 36.24 & 34.00 & 2.23 & 19 & 36.56 & 34.00 & 2.56 & 36.24 & 34.00 & 2.23 \\
\hline 35 & 20 & 37.60 & 35.00 & 2.59 & 21 & 37.87 & 36.00 & 1.87 & 37.64 & 36.00 & 1.63 \\
\hline 36 & 25 & 41.68 & 40.00 & 1.68 & 25 & 42.06 & 40.00 & 2.06 & 41.68 & 40.00 & 1.68 \\
\hline 37 & 18 & 24.90 & 23.01 & 1.89 & 19 & 26.86 & 24.00 & 2.86 & 25.13 & 24.01 & 1.12 \\
\hline 38 & 22 & 28.06 & 27.00 & 1.06 & 24 & 31.20 & 29.00 & 2.20 & 29.33 & 29.00 & 0.32 \\
\hline 39 & 22 & 29.12 & 27.00 & 2.11 & 26 & 32.92 & 31.00 & 1.92 & 31.34 & 31.00 & 0.34 \\
\hline 40 & 27 & 33.68 & 32.00 & 1.68 & 31 & 37.98 & 36.00 & 1.98 & 36.24 & 36.00 & 0.24 \\
\hline 41 & 18 & 48.32 & 45.53 & 2.79 & 17 & 48.00 & 44.50 & 3.50 & 48.35 & 44.55 & 3.81 \\
\hline 42 & 23 & 53.12 & 50.50 & 2.62 & 23 & 52.86 & 50.50 & 2.36 & 53.12 & 50.50 & 2.62 \\
\hline 43 & 25 & 54.78 & 52.50 & 2.28 & 25 & 54.72 & 52.50 & 2.22 & 54.78 & 52.50 & 2.28 \\
\hline 44 & 31 & 60.18 & 58.50 & 1.68 & 31 & 60.30 & 58.50 & 1.80 & 60.18 & 58.50 & 1.68 \\
\hline 45 & 21 & 31.09 & 28.52 & 2.57 & 21 & 32.84 & 28.50 & 4.34 & 31.09 & 28.52 & 2.57 \\
\hline 46 & 26 & 35.37 & 33.51 & 1.86 & 28 & 39.14 & 35.50 & 3.64 & 36.46 & 35.50 & 0.96 \\
\hline 47 & 27 & 37.15 & 34.50 & 2.64 & 31 & 41.54 & 38.50 & 3.04 & 38.96 & 38.50 & 0.46 \\
\hline 48 & 32 & 42.14 & 39.50 & 2.64 & 38 & 48.63 & 45.50 & 3.13 & 45.50 & 45.50 & 0.00 \\
\hline 49 & 24 & 47.04 & 43.99 & 3.05 & 25 & 47.22 & 45.00 & 2.22 & 47.08 & 44.99 & 2.09 \\
\hline 50 & 28 & 51.51 & 47.99 & 3.52 & 29 & 51.17 & 49.00 & 2.17 & 51.51 & 48.99 & 2.52 \\
\hline 51 & 31 & 52.93 & 50.99 & 1.94 & 31 & 52.80 & 51.00 & 1.80 & 52.93 & 50.99 & 1.94 \\
\hline 52 & 34 & 57.35 & 53.99 & 3.36 & 36 & 57.67 & 56.00 & 1.67 & 57.67 & 55.99 & 1.68 \\
\hline 53 & 24 & 47.04 & 43.99 & 3.05 & 28 & 50.85 & 48.00 & 2.85 & 48.69 & 47.99 & 0.70 \\
\hline 54 & 28 & 51.51 & 47.99 & 3.52 & 33 & 55.41 & 53.00 & 2.41 & 53.26 & 52.99 & 0.28 \\
\hline 55 & 31 & 52.93 & 50.99 & 1.94 & 35 & 57.24 & 55.00 & 2.24 & 55.23 & 54.99 & 0.24 \\
\hline 56 & 34 & 57.35 & 53.99 & 3.36 & 41 & 62.84 & 61.00 & 1.84 & 60.99 & 60.99 & 0.00 \\
\hline 57 & 28 & 92.33 & 88.01 & 4.32 & 28 & 92.54 & 88.00 & 4.54 & 92.33 & 88.01 & 4.32 \\
\hline 58 & 35 & 99.68 & 94.98 & 4.71 & 36 & 99.49 & 96.00 & 3.49 & 99.72 & 95.98 & 3.75 \\
\hline 59 & 38 & 102.61 & 97.97 & 4.63 & 38 & 102.15 & 98.00 & 4.15 & 102.61 & 97.97 & 4.63 \\
\hline 60 & 49 & 110.65 & 108.97 & 1.68 & 47 & 110.10 & 107.00 & 3.10 & 111.29 & 106.97 & 4.32 \\
\hline 61 & 32 & 56.67 & 51.99 & 4.68 & 33 & 59.41 & 53.00 & 6.41 & 56.74 & 52.98 & 3.76 \\
\hline 62 & 40 & 62.97 & 59.96 & 3.01 & 43 & 68.18 & 63.00 & 5.18 & 64.40 & 62.96 & 1.44 \\
\hline 63 & 42 & 65.73 & 61.96 & 3.77 & 47 & 71.53 & 67.00 & 4.53 & 67.68 & 66.96 & 0.72 \\
\hline 64 & 51 & 72.40 & 70.96 & 1.44 & 57 & 81.51 & 77.00 & 4.51 & 77.20 & 76.96 & 0.24 \\
\hline 65 & 30 & 146.28 & 140.12 & 6.16 & 29 & 146.25 & 139.00 & 7.25 & 146.28 & 139.15 & 7.13 \\
\hline 66 & 41 & 156.32 & 150.98 & 5.34 & 41 & 156.32 & 151.00 & 5.32 & 156.32 & 150.98 & 5.34 \\
\hline 67 & 45 & 160.20 & 154.96 & 5.23 & 45 & 160.06 & 155.00 & 5.06 & 160.20 & 154.96 & 5.23 \\
\hline 68 & 55 & 171.44 & 164.95 & 6.48 & 57 & 171.02 & 167.00 & 4.02 & 171.76 & 166.95 & 4.80 \\
\hline 69 & 36 & 71.97 & 66.03 & 5.94 & 35 & 74.45 & 65.00 & 9.45 & 72.16 & 65.05 & 7.11 \\
\hline
\end{tabular}




\begin{tabular}{|c|c|c|c|c|c|c|c|c|c|c|c|}
\hline 70 & 46 & 81.03 & 75.94 & 5.09 & 50 & 87.82 & 80.00 & 7.82 & 82.27 & 79.93 & 2.34 \\
\hline 71 & 49 & 84.60 & 78.93 & 5.67 & 56 & 92.72 & 86.00 & 6.72 & 86.89 & 85.93 & 0.96 \\
\hline 72 & 61 & 94.77 & 90.93 & 3.84 & 71 & 106.93 & 101.00 & 5.93 & 101.65 & 100.92 & 0.72 \\
\hline 73 & 49 & 154.67 & 149.02 & 5.65 & 49 & 155.25 & 149.00 & 6.25 & 154.67 & 149.02 & 5.65 \\
\hline 74 & 58 & 163.45 & 158.00 & 5.45 & 59 & 164.04 & 159.00 & 5.04 & 163.49 & 159.00 & 4.49 \\
\hline 75 & 62 & 167.14 & 162.00 & 5.14 & 63 & 167.51 & 163.00 & 4.51 & 167.37 & 163.00 & 4.37 \\
\hline 76 & 75 & 177.40 & 175.00 & 2.40 & 74 & 178.01 & 174.00 & 4.01 & 178.08 & 174.00 & 4.08 \\
\hline 77 & 49 & 154.67 & 149.02 & 5.65 & 56 & 162.72 & 156.00 & 6.72 & 157.68 & 156.00 & 1.67 \\
\hline 78 & 58 & 163.45 & 158.00 & 5.45 & 67 & 172.92 & 167.00 & 5.92 & 167.95 & 167.00 & 0.95 \\
\hline 79 & 62 & 167.14 & 162.00 & 5.14 & 71 & 176.93 & 171.00 & 5.93 & 171.76 & 171.00 & 0.77 \\
\hline 80 & 75 & 177.40 & 175.00 & 2.40 & 84 & 189.04 & 184.00 & 5.04 & 184.72 & 184.00 & 0.72 \\
\hline 81 & 52 & 363.34 & 352.24 & 11.11 & 52 & 363.82 & 352.00 & 11.82 & 363.34 & 352.24 & 11.11 \\
\hline 82 & 72 & 380.15 & 372.02 & 8.13 & 71 & 380.25 & 371.00 & 9.25 & 380.21 & 371.02 & 9.18 \\
\hline 83 & 78 & 385.47 & 378.01 & 7.47 & 78 & 386.40 & 378.00 & 8.40 & 385.47 & 378.01 & 7.47 \\
\hline 84 & 97 & 402.76 & 396.99 & 5.76 & 97 & 404.34 & 397.00 & 7.34 & 402.76 & 396.99 & 5.76 \\
\hline 85 & 64 & 173.60 & 164.14 & 9.47 & 62 & 176.69 & 162.00 & 14.69 & 173.85 & 162.17 & 11.68 \\
\hline 86 & 79 & 187.74 & 179.01 & 8.73 & 86 & 197.86 & 186.00 & 11.86 & 189.59 & 186.00 & 3.59 \\
\hline 87 & 86 & 193.18 & 186.00 & 7.18 & 95 & 205.69 & 195.00 & 10.69 & 197.20 & 194.99 & 2.21 \\
\hline 88 & 103 & 209.23 & 202.99 & 6.24 & 119 & 228.40 & 219.00 & 9.40 & 219.23 & 218.99 & 0.24 \\
\hline 89 & 49 & 617.36 & 600.17 & 17.19 & 49 & 617.53 & 599.00 & 18.53 & 617.36 & 600.17 & 17.19 \\
\hline 90 & 79 & 642.18 & 629.16 & 13.03 & 79 & 642.74 & 629.00 & 13.74 & 642.18 & 629.16 & 13.03 \\
\hline 91 & 89 & 651.28 & 639.08 & 12.20 & 89 & 651.66 & 639.00 & 12.66 & 651.28 & 639.08 & 12.20 \\
\hline 92 & 117 & 677.35 & 667.02 & 10.33 & 117 & 676.93 & 667.00 & 9.93 & 677.35 & 667.02 & 10.33 \\
\hline 93 & 69 & 233.36 & 219.52 & 13.85 & 54 & 230.84 & 204.00 & 26.84 & 241.16 & 205.38 & 35.78 \\
\hline 94 & 92 & 253.24 & 242.09 & 11.15 & 97 & 265.16 & 247.00 & 18.16 & 254.42 & 247.06 & 7.36 \\
\hline 95 & 100 & 261.22 & 250.05 & 11.17 & 111 & 277.02 & 261.00 & 16.02 & 264.94 & 261.02 & 3.91 \\
\hline 96 & 127 & 283.50 & 277.01 & 6.48 & 147 & 310.25 & 297.00 & 13.25 & 297.73 & 297.01 & 0.72 \\
\hline
\end{tabular}


Appendix 6: Results of numerical experiments for different values of $a \times \beta, T, m$, and $R$

\begin{tabular}{|c|c|c|c|c|c|c|c|c|c|c|c|}
\hline & \multicolumn{4}{|c|}{ Exact model (Optimal) } & \multicolumn{4}{|c|}{ Approximate model } & \multicolumn{3}{|c|}{ Exact model with $S S_{a}^{*}$} \\
\hline & $S S_{e}^{*}$ & $T C_{e}^{*}$ & $I H C_{e}^{*}$ & $\boldsymbol{R O C}_{e}^{*}$ & $S S_{a}^{*}$ & $T C_{a}^{*}$ & $I H C_{a}^{*}$ & $\boldsymbol{R O C} C_{a}^{*}$ & $T C_{e}^{*}\left(S S_{a}^{*}\right)$ & $\boldsymbol{I H C}_{\boldsymbol{e}}^{*}\left(\boldsymbol{S S _ { a } ^ { * } )}\right.$ & $\boldsymbol{R O C}_{\boldsymbol{e}}^{*}\left(\boldsymbol{S S}_{a}^{*}\right)$ \\
\hline$a \times \beta=1$ & 10.83 & 14.03 & 13.01 & 1.02 & 11.25 & 14.55 & 13.42 & 1.13 & 14.30 & 13.42 & 0.87 \\
\hline$a \times \beta=5$ & 20.92 & 33.57 & 31.76 & 1.82 & 22.33 & 35.30 & 33.17 & 2.13 & 34.33 & 33.17 & 1.16 \\
\hline$a \times \beta=20$ & 38.00 & 85.30 & 81.32 & 3.99 & 40.46 & 88.15 & 83.79 & 4.36 & 86.54 & 83.77 & 2.76 \\
\hline$a \times \beta=100$ & 76.71 & 301.68 & 293.48 & 8.20 & 80.25 & 307.58 & 296.92 & 10.67 & 304.32 & 297.06 & 7.27 \\
\hline$m=1$ & 35.04 & 138.79 & 134.83 & 3.96 & 35.13 & 138.85 & 134.88 & 3.97 & 138.89 & 134.91 & 3.97 \\
\hline$m=5$ & 38.19 & 78.50 & 74.95 & 3.55 & 42.02 & 83.94 & 78.77 & 5.17 & 80.86 & 78.80 & 2.06 \\
\hline$T=1$ & 28.69 & 62.62 & 60.19 & 2.44 & 31.06 & 64.94 & 62.56 & 2.38 & 63.79 & 62.56 & 1.23 \\
\hline$T=5$ & 37.59 & 104.21 & 100.60 & 3.60 & 39.44 & 106.97 & 102.44 & 4.53 & 105.24 & 102.45 & 2.79 \\
\hline$T=10$ & 43.56 & 159.11 & 153.88 & 5.23 & 45.22 & 162.28 & 155.47 & 6.81 & 160.58 & 155.56 & 5.02 \\
\hline$R=10$ & 27.33 & 100.26 & 95.68 & 4.58 & 27.29 & 101.39 & 95.54 & 5.84 & 100.87 & 95.68 & 5.19 \\
\hline $\boldsymbol{R}=50$ & 35.00 & 107.12 & 103.26 & 3.86 & 36.79 & 109.66 & 105.04 & 4.62 & 107.84 & 105.05 & 2.79 \\
\hline $\boldsymbol{R}=100$ & 37.79 & 109.79 & 106.04 & 3.75 & 40.33 & 112.75 & 108.58 & 4.17 & 110.87 & 108.58 & 2.29 \\
\hline $\boldsymbol{R}=1000$ & 46.33 & 117.42 & 114.58 & 2.84 & 49.88 & 121.79 & 118.13 & 3.66 & 119.91 & 118.12 & 1.79 \\
\hline All scenarios & 36.61 & 108.65 & 104.89 & 3.76 & 38.57 & 111.40 & 106.82 & 4.57 & 109.87 & 106.86 & 3.02 \\
\hline
\end{tabular}

